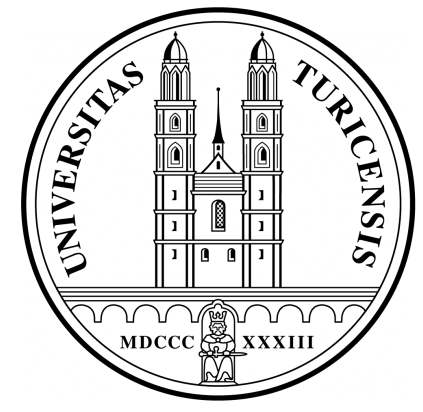

Institute for Strategy and Business Economics

University of Zurich

Working Paper Series

ISSN 1660-1157

Working Paper No. 74

Talent and/or Popularity - What Does it Take to Be a Superstar?

Egon Franck and Stephan Nüesch

September 2009 


\title{
Talent and/or Popularity: What Does it Take to Be a Superstar?
}

\author{
Egon Franck, ${ }^{*}$ Stephan Nüesch ${ }^{+}$
}

This version: September 2009 (first version: November 2007)

\begin{abstract}
We show that both talent and popularity significantly contribute to stars' market values in German soccer. The talent-versus-popularity controversy on the sources of stardom goes back to Rosen (1981) and Adler (1985). All attempts to resolve the controversy empirically face the difficulty of accurately identifying talent. In professional sports, rank-order tournaments help in ascertaining talent. Analyzing a team production setting, we make use of a large number of performance indicators to estimate a player's talent according to his contribution to the team's winning chances.
\end{abstract}

JEL Classification: J 31, J 44, L 83

* Egon Franck, University of Zürich, Institute for Strategy and Business Economics, Plattenstrasse 14, CH8032 Zürich, egon.franck@isu.uzh.ch, phone: +41 4463428 45, fax: +41 446344348.

+ Corresponding author: Stephan Nüesch, University of Zurich, Institute for Strategy and Business Economics, Plattenstrasse 14, CH-8032 Zürich, stephan.nuesch@isu.uzh.ch, phone: +41 4463429 14, fax: +41 446344348 .

We are grateful to Leif Brandes, Stefan Szymanski, Rainer Winkelmann, two anonymous referees, and to the seminar participants at the Western Economic Association conference 2007 in Seattle, the Workshop of Commission of Organization 2008 in Munich, the Annual Meeting of the German Academic Association for Business Research 2008 in Berlin for helpful comments. Remaining errors are, of course, our own. 
"The phenomenon of Superstars, wherein relatively small numbers of people earn enormous amounts of money and dominate the activities in which they engage, seems to be increasingly important in the modern world" (Rosen 1981, 845, own emphasis).

\section{INTRODUCTION}

The opening sentence of Sherwin Rosen's seminal paper "The Economics of Superstars" today applies more than ever. Technological change has enlarged the scope and the intensity of so-called winner-takes-all markets in the last decades. The central question addressed in this paper is: What does it take to be a superstar? Why do some artists, media stars, professional athletes or executives earn disproportionately high salaries while others receive comparably low remuneration? In the literature, there are basically two competingbut not mutually exclusive - theories of superstar formation proposed by Rosen (1981) and Adler (1985). ${ }^{1}$ While Sherwin Rosen explains how small differences in talent translate into large differences in earnings, Moshe Adler argues that superstars might even emerge among equally talented performers due to the positive network externalities of popularity. Empirical tests of the different driving forces of superstar salaries have proved to be very difficult because an objective measure of a star's talent is often hard to find and even harder to quantify (Krueger 2005). For example, what are the talent characteristics of a pop music star? The literature offers different approaches. Hamlen $(1991,1994)$ uses the physical concept of "voice quality", which measures the frequency of harmonic content that singers use when they sing the word "love" in one of their songs_-but does this really matter for pop music? Krueger (2005) measures star quality by the number of millimeters of print columns devoted to each artist in The Rolling Stone Encyclopedia of Rock \& Roll. Nevertheless, as he admits, this measure reflects the subjective importance the editors of the Encyclopedia implicitly devote to each artist, which may correlate both with the artist's talent and with his/her popularity. In team production settings, the difficulty of accurately measuring star talent is even more intense, as individual contributions to team output is mostly unclear. However, the empirical relevance of stars within teams is undoubted. Star CEOs in top management teams, lead singers of rock bands or star athletes on sports teams are just a few examples of superstars embedded in teams.

\footnotetext{
${ }^{1}$ There are, of course, other superstar theories as well (e.g. MacDonald 1988; Kremer 1993; Frank and Cook, 1995; or Borghans and Groot 1998). The basic principles of Rosen (1981) and Adler (1985) have remained omnipresent, however.
} 
This paper argues that rank-order tournaments in professional sports allow a more accurate determination of talent than occurs in the arts. In individual sports, direct competitions help ascertaining the most talented athletes. The common rules of the game have the character of a fixed effect that allows relative evaluations (Frick 2003). Even though each athlete's performance is also affected by random causes, it can typically be assumed that the most talented athlete enjoys the highest probability of winning. In team sports, however, teams and not individual players compete in rank-order tournaments. As we examine superstars in a team production setting, namely in professional soccer, we first estimate a team production function to identify the playing characteristics that significantly influence the probability of a team winning. In doing so, we use the detailed statistics of the Opta Sports Data Company, which quantifies and qualifies every touch of the ball during the game by each player. In a second step, we use the individual performance statistics of all variables that have proved to be critical for winning as indicators of the player's talent and estimate the impact of talent, popularity and various controls on the player's market value, employing individual panel data from the highest German soccer league. A player's popularity is measured by the annual press publicity he receives in over 20 different newspapers and magazines, purged of positive influences of field performance so that our popularity indicator captures the non-performance-related celebrity status of a player. Since we define superstars as a relatively small number of players at the top end of the league's market value distribution, we run different quantile regressions that allow us to characterize a particular point in the conditional distribution. We find empirical evidence that both talent and nonperformance-related popularity increase the market values of soccer stars. The marginal influence of talent is magnified near the top end of scale, as postulated by Rosen's star theory. While one additional goal scored increases a player's market value by $€ 0.06$ million at the mean, the impact increases to $€ 0.25$ million at the $95 \%$ quantile. Using team revenue data, we find that the magnitude of the talent effect is plausible given the large returns to scale in German soccer.

Our focus differs from that of previous literature that examines the relationship between star attraction and team revenues ${ }^{2}$ and from papers that estimate individual marginal revenue

\footnotetext{
${ }^{2}$ See, e.g., Hausman and Leonard (1997); Mullin and Dunn (2002); Berri, Schmidt, and Brook (2004); or Brandes, Franck, and Nüesch (2008).
} 
products. $^{3}$ Instead, we investigate the relationship between a star's characteristics and his labor market demand.

The remainder of the paper is organized as follows. Section two illustrates the two alternative theories of superstar formation and their hypotheses. Section three presents the related empirical literature. In section four, we explain the difficulty of adequately measuring talent and the advantages the sports industry offers. Subsequently, we test the relevance of numerous field performance measures as talent indicators. The popularity measure is explicated in section five. Section six includes the main empirical analysis that relates the stars' market values to their characteristics before we conduct a few sensitivity analyses in section seven. The last section discusses results and possible implications.

\section{THEORIES OF SUPERSTAR FORMATION}

Alfred Marshall (1947) has already pointed out that innovations in technology and mass production will lower the per-unit price of quality goods and ultimately allow higher-quality goods to obtain a greater market share. In 1981, Sherwin Rosen named this effect the "superstar phenomenon". Extraordinary salaries earned by superstars are driven by a market equilibrium that rewards talented people with increasing returns to ability. The key to the high earnings of superstars lies in the vast audience they are able to reach due to scale economies. Superstars arise in markets in which the production technology allows for joint consumption. For example, if one person watches a tennis game on television, this does not diminish someone else's opportunity to watch it as well. In superstar industries production costs do not rise in proportion to the size of the seller's market. This enables a few or just one supplier to serve the whole market.

However, large economies of scale do not guarantee high salaries for a small number of stars unless the market demand becomes highly concentrated on their services. In the superstar literature, the demand for superstar services is basically driven by two distinct but not mutually exclusive factors: superior talent, according to Rosen (1981), and network externalities of popularity, according to Adler (1985).

Firstly, market demand may be concentrated on superstars due to their superior talent. Rosen (1981) argues that poorer quality is only an imperfect substitute for higher quality.

\footnotetext{
${ }^{3}$ A prominent example is the paper of Scully (1974).
} 
Thus, people prefer consuming fewer high-quality services to more of the same service at moderate quality levels: “(...) hearing a succession of mediocre singers does not add up to a single outstanding performance" (Rosen 1981, 846). Most people tend not to be satisfied with the performance of a less talented but cheaper artist when they are able to enjoy a top performance, even if the costs are somewhat higher (Frey 1998). This sort of imperfect substitutability applies in particular to status goods or gifts: To celebrate a special occasion, people search not for an average restaurant meal or bottle of wine, but for the best (Frank and Cook 1995). According to Rosen (1981), small differences in talent among performers are magnified into large earnings differentials. Rosen stars are simply better than their rivals. In professional sports, they attract fans with their outstanding performances.

Network externalities of popularity offer a second explanation of why demand may be highly focused on the services of a few superstars. In contrast to the typical standardization literature $^{4}$, the network externalities of superstars are not confined to issues of technological compatibility or a larger variety of complements. Moshe Adler, rather, suggests a cognitive and social form of network externalities. Adler (1985) argues that the marginal utility from consuming a superstar service increases with the ability to appreciate it, which depends not only on the star's talent, but also on the amount of star-specific knowledge the consumer has acquired. This specific knowledge — called consumption capital—is accumulated through past consumption activities or by discussing the star's performance with likewise knowledgeable individuals. The latter effect gives rise to positive network externalities. The more popular the artist is, the easier it becomes to find other fans. Searching cost economies imply that consumers are better off patronizing the most popular star as long as others are not perceived as clearly superior.

"Stardom is a market device to economize on learning costs in activities where "the more you know the more you enjoy." Thus stardom may be independent of the existence of a hierarchy of talent" (Adler 1985, 208-209).

According to Adler (1985), luck (by luck, he means factors other than talent) determines who amongst equally talented artist will snowball into a star. Superstars may emerge because initially (slightly) more people happen to know one artist than any other in a group of artists of possibly equal talent. However, more than twenty years later, Adler (2006) dismisses the idea of luck as the only possible mechanism driving the initial selection from among equally talented people. Future superstars do not usually entrust this choice to pure

\footnotetext{
${ }^{4}$ See, e.g., Katz and Shapiro (1985) or Farrell and Saloner (1985).
} 
chance. Instead, they consciously use publicity, such as appearances on talk shows and coverage in tabloids, magazines, newspapers, and the Internet to signal and strengthen their popularity. Adler (2006) emphasizes that consumption capital is acquired not only through past consumption activities and discussions but also by reading about the star's performance in newspapers, in magazines and on the Internet. On the one hand, publicity directly reduces the costs of learning about star services; on the other hand, it is also a good indicator of the star's popularity in society.

Both Rosen (1981) and Adler (1985) agree that superstars provide services of superior perceived quality. But whereas according to Rosen (1981) the star's talent alone determines the perceived quality, Adler (1985) argues that factors other than talent, like popularity, matter too. Thus, Adler's superstar theory does not contradict Rosen's star model but rather supplements it. In team sports, for example, superstars may have personal appeal or charisma, an element that activates fan interest even after controlling for their contribution to the team's (increased) playing quality.

\section{RELATED EMPIRICAL LITERATURE}

In this section, we give an introduction to the existing empirical literature on superstar emergence. A first body of literature relates star remuneration to talent proxies but does not include separate explanatory variables distinguishing the Adler effect.

Hamlen (1991 and 1994) empirically tests Rosen's superstar assumption that small differences in talent become magnified into disproportional levels of financial success in the popular music industry. He uses the harmonic content of the singer's voice as a talent measure. Harmonic content is a clearly quantifiable variable that measures the "richness" and "depth" of the singer's voice (Hamlen 1991, 731). When controlling for other factors like gender, race, type of music, and career duration, he shows that the estimated elasticity of record sales to "voice quality" is significantly greater than zero but less than one. Thus, he fails to find a magnification effect. ${ }^{5}$ In his 1994 paper, Hamlen finds that the single market acts as an (imperfect) "quality" filter for the albums market. Hence, a representative consumer is more likely to purchase albums by singers who have already been successful in

\footnotetext{
${ }^{5}$ Krueger (2005) objects that Hamlen's interpretation of the low elasticity as a rejection of Rosen's star model might be wrong, because it is unclear whether the scaling of units of quality is appropriate and that the elasticity may be above 1 when using a different scaling.
} 
the singles market. This filtering process is imperfect, however, which is in line with Adler's superstar theory.

Frick (2001) and Lucifora and Simmons (2003) use data from professional team sports to analyze stars. Frick (2001) finds evidence to support Rosen's explanation of superstars, showing that performance measures like numbers of scores, rebounds, steals, assists and blocks will predict the rising salary differentials of basketball players in the National Basketball Association (NBA). The same applies to scores and assists by hockey players in the National Hockey League (NHL). Lucifora and Simmons (2003) investigate wage determination among professional soccer players appearing in the Italian league. They show that talent-measured by the number of goals and assists scored per game-exercises significant influence on the skewness of the salary distribution of forwards and midfield players.

As already mentioned in the introduction, Krueger (2005) uses a rather novel approach to measure the star quality of rock \& roll musicians: number of millimeters of print in columns devoted to each artist in The Rolling Stone Encyclopedia of Rock \& Roll. Although this is a subjective measure, the number of millimeters of print still has the virtue of reflecting the importance that the editors of the Encyclopedia implicitly attach to each artist. Thus, it might be correlated with both the artist's talent and with his/her popularity. Krueger (2005) finds evidence that the returns to superstardom in terms of ticket price, annual revenue and revenue per show have increased over time due to technology changes.

Since any objective quality is surely multidimensional, a second body of related empirical literature does not even attempt to locate appropriate ability indicators but instead tests whether market outcomes could be merely the result of a probability mechanism determining that "outputs will be concentrated among a few lucky individuals" (Chung and Cox 1994, 771, emphasis in original). This concept is, in its spirit, similar to the ideas of Adler (1985). Schulze (2003) criticizes this body of literature because the question regarding the underlying reason for a consumer's decision to buy a star's service remains unanswered.

Using a stochastic model by Yule (1924) and Simon (1955) as a representation of the consumer's choice behavior, Chung and Cox (1994) show that the superstar phenomenon does not require talent differentials. They argue that the very large incomes of superstars in the popular music industry are driven by sheer fortune rather than by superior talent. Luck initially increases popularity and triggers a self-reinforcing bandwagon effect. 
Giles (2006) contradicts the findings of Chung and Cox (1994), as he does not find evidence that either the lifetime or the quantity of number-one hits in the US popular music industry is spread according to the Yule distribution. He leaves open whether Rosen's or Adler's superstar explanation is relevant to the music industry and agrees with Connoly and Krueger $(2006,696)$ that the "inherent difficulty of objectively measuring talent or quality in a meaningful metric apart from economic success" is one of the main obstacles to testing superstar theories.

Instead of explaining remuneration or any other outcome variables as based on characteristics of the superstar, Crain and Tollison (2002) regress the artist concentration in a market on several socio-demographic factors like the teenage share of population, the death rate of active-duty military or the inflation rate. They find, for example, that the teenage share of the population increases the market concentration in popular music. Younger consumers have a longer consumption horizon, which strengthens the incentives to switch to the superstar and abandon the non-star. Thus, the skewness of the market outcomes in the popular music industry is driven by the fact that consumers are economizing on costly consumption capital, which is in line with Adler's conception of superstar emergence. But, as stated above, Crain and Tollison (2002) do not control for quality differentials, even though they admit that some underlying and objective measures of quality differences are essential to the test of both the Rosen and the Adler hypothesis.

A third body of related literature uses both talent and popularity proxies in its empirical framework. Lehmann and Schulze (2008), as well as Franck and Nüesch (2008), test the influence of field performance and media publicity on the emergence of superstars in German soccer. Regressing salary proxies of 359 players on three performance measures (goals, assists and tackles) and the number of citations in the online version of the soccer magazine Kicker, Lehmann and Schulze (2008) discover that neither performance nor publicity can explain the salaries of superstars in the $95 \%$ quantile. Franck and Nüesch (2008) find contrary evidence; not only talent-measured by expert opinions-but also popularity increases the demand for star players. Both Lehmann und Schulze (2008) and Franck and Nüesch (2008) use cross-sectional samples and consider the talent indicators as exogenously given without proving their relevance for a soccer game.

Salganik, Dodds and Watts (2006) used an experimental study to investigate both the talent and the popularity hypothesis in an artificial cultural market. 14,341 participants downloaded previously unknown songs either with or without knowledge regarding previous 
participants' choices. The participants were randomly assigned to one of two experimental conditions distinguished only by the availability of information on the previous choices of others. Salganik et al. (2006) show that the information regarding the choices of others contributes to both the inequality and the unpredictability of the artificial music market. Social influence increases the skewness of the market distribution and the unpredictability of success. The latter is analyzed as the extent to which two "worlds" with identical songs, identical initial conditions, and indistinguishable populations generate different outcomes. Since the outcome is unpredictable even when consumers had no knowledge about download statistics, they conclude that no measure of a song's quality can precisely predict success.

\section{TALENT DETERMINATION}

If one conclusion may be drawn from the existing superstar literature, it is the recognition of not only the difficulty but also the necessity of finding accurate talent measures in order to distinguish between Rosen's and Adler's star concepts. Throsby (1994, 19) writes:

"While it is quite plausible to take estimated earnings functions and to attribute at least some of the (often large) unexplained residual to differences in talent, such a hypothesis remains untestable when no independent measure of talent is forthcoming."

Hamlen (1994, 405) calls a "sour grapes conclusion" any conclusion drawn when scholars believe they have found empirical evidence of the superstar phenomenon by examining only measures of success and failing to compare these to some objective and external measure of quality or ability. "A proper test of the superstar phenomenon requires that the measure of "quality" ("ability") be an external measure." (Hamlen 1994, 399).

The first issue in terms of talent determination is its validity. While some pop fans love the music of Madonna, others may hate it. In the popular music industry, talent is hard to define. Some music appeals to a subset of listeners but not to others because, in the arts, there is "an intrinsically subjective component to quality" (Connolly and Krueger 2006, 697). Both Rosen (1981) and Adler (1985), however, assume identical consumers who demand an equal unspecified artistic activity. They argue that diversity of tastes does not change the basic mechanisms of superstar formation but simply confines a sellers' market. Consumers of similar taste constitute a market with its own stars. As stated previously, Hamlen (1991) uses the harmonic content of the voice as a singer's talent indicator. Still, does harmonic content 
of the voice really matter? In classical music or opera, presumably yes. In the case of pop or rock music, however, we have strong doubts about the relevance of harmonic content of the voice. More important factors for the success of such singers are probably charm, sex appeal, or the show on stage. Hence, one possibility for dealing with heterogeneous tastes is to use specific talent indicators only within a genre: otherwise, how is it possible to compare a chamber orchestra with a heavy metal band? Nevertheless, quality perceptions often differ even within a particular genre.

A second obstacle experienced in the context of empirical superstar studies is the measurement of talent. The absence of "natural units" for measuring talent is a major limitation of empirical superstar studies in the arts (Connoly and Krueger 2006). Even if all pop fans agreed that charisma on stage is the most important ability of a pop star, scholars would still face the difficulty of capturing charisma on a metrical scale. Talent is inherent and thus hard to quantify.

In professional sports, the empirical problems described above are less serious because valid talent measures are easier to find than in other fields like the arts or entertainment activities (Schulze 2003). In professional sports, the winners are determined by a set of wellestablished tournaments relying either on objective quality indicators like goal scoring and/or on institutionalized voting procedures by proven expert judges. Rank-order tournaments in professional sports may be considered a mechanism for identifying an athlete's talent. Although different effort levels and uncontrollable factors like wrong referee decisions or pure luck might also affect the final result, the competition is generally won by the most talented athlete. Since innate talent is unobservable, Rosen (1981) argues that any cardinal measure of talent must rely on measurements of actual outcomes. In individual sports, the probability of winning is this sort of measurable outcome and serves, therefore, as a good indicator of the athlete's talent. Even though a high likelihood of winning marks high sportive success, it does not necessarily imply enormous salaries as well. Or inversely, even less talented and thus less successful athletes might earn superstar wages. ${ }^{6}$ So, there is no danger of a tautological Rosen star definition.

\footnotetext{
${ }^{6}$ The Russian tennis player Anna Kournikova serves as a good illustration here. She did not achieve any significant success in single tournaments and her overall single ranking was never better than eight. Nevertheless, in 2002 she was the second highest earner in female tennis behind Venus Williams, the number one at the time. In Kournikova's case, sponsorships and other lucrative commercial opportunities have arisen not from a consistent record of successful performances on the tennis court, but instead as a consequence of an image of sexual attractiveness and an associated media profile.
} 
Analyzing stardom in team production settings, talent determination is more complex. It requires a proper evaluation of the team production technology because teams - and not individuals - compete in rank-order tournaments. In this paper, the (Rosen) talent of a soccer star is considered the player's ability to increase the winning chances of his team. Thus, talent represents pure on-the-field prowess. Other fan attraction abilities of stars like celebrity status or being a pop icon are, as Adler $(1985,211)$ writes, "factors other than talent". Defining talent as the ability to increase the team's winning probability, we first need to estimate individual contributions to the team output. In doing so, we make use of a large series of performance categories (e.g., shots at goal, passes, clearances, tackles, or dribbles) provided by the Opta Sports Data Company, which quantifies and qualifies every touch of the ball by each player during the game based on live and off-tape analysis of every match by a team of specialist analysts.

Using data for all games in the highest German soccer league during five seasons (2001/02 - 2005/06), we empirically estimate a team production function in order to identify all playing elements that significantly increase (or reduce) the team's winning probability. Unlike in many estimations of team production in professional sports, ${ }^{7}$ we do not estimate a player's marginal product or coaching efficiency, rates of monopsonistic exploitation, racial discrimination or any other important issue in labor economics. We simply identify significant correlations between various performance characteristics and winning in order to capture the dimensions of soccer talent.

Winning a soccer game is directly linked to the number of goals scored in relation to the number of goals conceded. Thus, team performance is measured in terms of the final score expressed as the goal differential. Team $i$ wins the game if it scores more goals $Y_{i t}$ than the opposition team $j$. If the goal differential is zero, the teams have tied, and if the goal difference is negative, team $i$ has lost. Inspired by Carmichael et al. (2000), we construct a team production function where the goal difference $\left(Y_{i t}-Y_{j t}\right)$ is determined by a vector of differences of play variables $\left(x_{i t}^{\prime}-x_{j t}^{\prime}\right)$, team fixed effects for both competing teams $\left(\delta_{i}, \delta_{j}\right)$, a dummy variable indicating whether team $i$ is playing at home $\left(H O M E_{i t}\right)$ and an error term $\left(\varepsilon_{i j t}\right)$ :

$$
Y_{i t}-Y_{j t}=\alpha+\beta\left(x_{i t}^{\prime}-x_{j t}^{\prime}\right)+\gamma H O M E_{i t}+\delta_{i}+\delta_{j}+\varepsilon_{i j t}
$$

\footnotetext{
${ }^{7}$ See, e.g., Scully (1974), Zak, Huan, and Siegfried (1979), Blass (1992), Berri (1999), or Carmichael, Thomas, and Ward (2000).
} 
While the dummy variable $H O M E_{i t}$ captures a potential home-field advantage, the team fixed effects account for any unobserved team characteristics that may influence the game's result beyond the analyzed play variables. The common occurrence of zero values for the dependent (e.g., scoreless draw results) and independent variables requires that the field performance variables be expressed as differences between the two opposing teams instead of ratios and that the production function be linearly specified instead of employing a multiplicative model. ${ }^{8}$ We do not estimate separate models for goals scored $Y_{i t}$ and goals conceded $Y_{j t}$, as soccer is - unlike, for example, baseball-a very interactive game in which success is achieved through the constant mutual cooperation of both offensive and defensive players. $^{9}$

With 18 teams each playing each other twice during the season, the full season fixture in the highest German soccer league includes 306 games generating 612 individual team performance observations. Since the dataset comprehends five seasons (2001/02-2005/06), we have 3060 team performances in 1530 games. However, only half of the observations are used to avoid double counting. Each of the 1530 observations relates to a different fixture, and for each season, the total is equally divided between home and away teams as well as between all participating teams in order to prevent selection bias.

[Table 1 about here]

Table 1 illustrates the variables and the descriptive statistics of the different play variables used to estimate equation 1 . We group the different performance measures offered by the Opta Sports Data Company in attacking plays, defensive plays, efficiency plays and aggressive plays. Since the likelihood of goal scoring is directly linked to shots at goal, all three attacking variables concern different "qualities" of shots at goal. While the number of shots on target and shots hitting the (goal net) woodwork are expected to be a sign of high

\footnotetext{
${ }^{8}$ We are aware that the assumption of additive separability of the playing statistics is problematic in soccer due to the high degree of interaction. Thus, we also tried to use seasonal data to prevent the issue of zero numbers (which is a necessary condition for using a double-logged, multiplicative model). However, even on the seasonal level, some of the variables have zero values (e.g., the number of red cards or balls dropped by the goalkeeper).

${ }^{9}$ However, separate models, in which the number of goals scored (conceded) is explained by (the opposing team's) attacking strength and the opposing team's (own) defensive quality, would provide qualitatively similar results.
} 
attacking quality, the impact of shots off target is ambiguous. On the one hand, it might be an indicator of high attacking pressure and a lot of goal scoring opportunities and attempts; on the other hand, it may also be a sign of low efficiency in goal scoring. The four variables characterizing defensive quality are the number of clearances, blocks and interceptions, the saves to shots ratio by the goalkeeper, the number of times the ball was caught by the goalkeeper and number of times the ball was dropped by the goalkeeper. The first variable reflects the ability to block and intercept the opposition's passes and shots and to clear the ball from pressure situations, while the last three defensive play variables address the playing talent of the goalkeepers, which incorporates the ability to save shots and to catch balls instead of dropping them. In addition, we test the influence of five different efficiency plays: the success rates for passes, flicks, crossings, dribblings and tackles, which should exert a positive influence on winning. The success rate is defined as the percentage of passes, flicks or crossings to one's own teammates in relation to the total of passes, flicks or crossings. Successful dribbling is dribbling in which the player is able to retain possession of the ball, whereas a successful tackle is a situation in which the player is able to snatch the ball from the other team. The last group includes aggressive plays. The numbers of red and yellow cards are expected to decrease the team's probability of winning. To be sent off the field by receiving a red card not only reduces the number of fielded players, but is also likely to have negative implications for overall team effectiveness. The magnitude of the effect of receiving a yellow card is expected to be smaller, as the player is just warned and may therefore play less intensely for the rest of the game. The other four variables indicate the team's differences in terms of fouls and hands, which may have ambiguous effects on the probability of winning. In a negative sense, such infringements may indicate an inability to deal with attacking pressure and/or lack of discipline. On the other hand, fouls may also prevent an opposing team from creating or taking advantage of scoring opportunities (Carmichael et al., 2000). We distinguish between three areas in which a foul is conceded: fouls conceded in the penalty area, in one's own third of the playing area, and not in one's own third of the playing field. Whereas fouls in the penalty area are expected to decrease the team's winning probability, the signs of the effects of fouls outside the penalty area are unclear a priori.

Due to the issue of multicollinearity, we did not include all variables that are provided by the Opta Sports Data Company. Two examples: Opta measures the number of key passes defined as passes leading to goal shots. Even though this information is of high interest and certainly impacts goal scoring, we did not include this information in our model because it is 
highly correlated with shots on and off target or hitting the (goal net) woodwork. Secondly, some of the attacking variables like shots on target have a very high correlation with some of the defense characteristics like saved shots by the opposite goalkeeper. The correlations between the chosen independent variables are below 0.6, and the mean variance inflation factor (VIF) is well below 2. The following Table 2 illustrates the estimation results of equation 1 .

[Table 2 about here]

We find evidence that team success is positively associated with shots on target and negatively related to shots off target. Thus, it seems that the quality and accuracy of shooting is more important than the pure number of shot attempts. Shots hitting the woodwork do not significantly affect team performance. The number of clearances, blocks and interceptions, as well as the saves to shots ratio by the goalkeeper, clearly increases the winning chances by preventing goal scoring on the part of the opposing team. The other defensive plays have no significant influence on the dependent variable. Regarding the efficiency plays, we see that the percentage of successful crossings has the highest impact on winning. The estimated coefficients of the other efficiency plays are not statistically significant. The infringement variables, red and yellow cards, appear as predicted with negative coefficients. The effect of a foul depends on where the foul is conceded. Whereas a foul causing a penalty significantly reduces the team's probability of winning, fouls outside the penalty area have no distinct impact on winning. The latter also applies to the number of hands.

We consider all individual field plays that have been proven to significantly affect the team's winning probability as characteristics of the unobserved talent of a player. The individual number of goals and assists, which are by definition directly related to the team's sportive performance, are used as talent indicators as well. ${ }^{10}$ In the next section, we explain how we measure the non-performance-related popularity of a player before both talent and popularity are related to the player's market value.

\footnotetext{
${ }^{10}$ Even though goals are strongly associated with, e.g., shots on target on the team level, the same does not necessarily hold on the individual level. Thus, we do not introduce systematic multicollinearity.
} 


\section{NON-PERFORMANCE-RELATED POPULARITY}

In line with Adler (2006) we proxy a player's popularity based on press publicity. Using the LexisNexis database, which contains more than 20 different quality nationwide newspapers (including Frankfurter Allgemeine Zeitung, Süddeutsche Zeitung, Stuttgarter Zeitung, Hamburger Abendblatt, Die Welt, taz, Berliner Morgenpost, Financial Times Deutschland) as well as weekly magazines (including Der Spiegel, Stern, Bunte), we count the number of articles in which a player is mentioned at least once. The search string included the first and last names of the player, as well as the name of the club he was engaged by during the corresponding season, starting from July $1^{\text {st }}$ at the beginning of the season and lasting until the $30^{\text {th }}$ of June at the end of the season.

As talent is measured by the player's field performance and popularity by the player's press publicity, the concepts of talent and popularity are likely to be positively correlated due to performance-related publicity. A top goal scorer usually enjoys more media attention than do players with mediocre field performance. In order to clearly differentiate between Rosen's and Adler's superstar theory, we need, however, a popularity measure that is unrelated to the performance of the player. Thus, we proxy a player's non-performance-related star attraction by the residuals $\varepsilon_{i t}$ of the following equation,

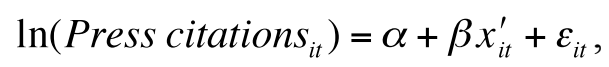

where the logarithm of articles mentioning the player's name is regressed on the critical individual field performance measures $x_{i t}^{\prime}$ according to the previous section. ${ }^{11}$ The ordinary least squares (OLS) estimation results of equation 2 are illustrated in Table 10 in the appendix of this paper. Most field performance measures significantly increase press coverage, with the highest magnitudes for goals, the saves to shots ratio, and assists. The residuals of equation 2 characterize a player's publicity that cannot be explained by his sportive performance on the pitch; for example, media publicity that is a result of the star having an affair or consciously presenting himself not only as a soccer star but as a pop icon as well. $^{12}$

\footnotetext{
${ }^{11} \mathrm{We}$ are grateful to an anonymous referee for proposing this procedure.

12 The ceteris paribus condition in multiple regression analysis is technically the same as if one were to introduce the residuals of a regression of the considered explanatory variable on all other explanatory variables (Wooldridge 2003, 78-79). The estimated popularity effect would therefore be the same if we directly introduced the logarithm of press citations into the model. The size of the talent effect would be comparably lower, however, as the positive correlation with performance-related popularity would be partialed out. By introducing the non-performance-related publicity of a player that - per construction-does not correlate with a
} 


\section{SUPERSTAR DETERMINANTS}

Data sample and dependent variable

The different theories of superstar formation are tested using panel data for players appearing in the highest German soccer league during five seasons (2001/02 until 2005/06). Whereas a lot of detailed statistics on individual productivity are available for players in top European leagues, individual salary data are (unlike for the US Major Leagues) not available, unfortunately. German soccer clubs are not required to publish player salaries. In 1995, the well-respected soccer magazine Kicker, however, began to publish estimates of the market values of the players appearing in the highest German soccer league. Since the market value proxies have been estimated in a systematic manner for several years by an almost identical, qualified editorial board, they are likely to be consistent and have, therefore, been used in several empirical studies so far (e.g., Hübl and Swieter 2002; Haas, Kocher, and Sutter 2004; Eschweiler and Vieth 2004; Kern and Süssmuth 2005; Torgler and Schmidt 2007; Torgler, Schaffner, Schmidt, and Frey 2008; Schmidt, Torgler, and Frey 2009). In line with most of the previous studies, ${ }^{13}$ we also use the market value proxies provided by the Kicker soccer magazine. Kicker is the only source that provides systematic panel data, and its reliability is judged to be high in the review articles of Torgler and Schmidt (2007) and Frick (2007). We additionally test the reliability of the market value data by comparing a Kicker subsample with a cross-section of market values provided by a second independent source, namely the webpage www.transfermarkt.de. The market value proxies of the two sources are highly correlated (correlation is 0.89), and the estimation results are very similar if the Transfermarkt data is employed, as we show in our first sensitivity analysis in section VII of this paper. The fact that separate regressions using different data sources lead to the same results increases confidence in the reliability of our results.

Mentioning the examples of full-time comedians and soloists, Rosen (1981) considered stars as individual service providers with enormous earnings. The earnings of painters, authors or athletes in individual sports are directly determined by the market potential of their

player's performance, we are able to estimate unrestricted talent effects. In other words, we use the residuals of equation 2 as measure of a player's popularity because we want to net out the influence of performance on publicity, but not the other way around.

${ }^{13}$ Other studies use cross-sectional samples of remuneration estimates of players from the 1999/00 season published in Welt am Sonntag (Lehmann and Weigand 1999), in Sportbild (Lehmann and Schulze 2008), or on the webpage www.transfermarkt.de (Eschweiler and Vieth 2004; Franck and Nüesch 2008). 
services. So, market value and remuneration are, generally speaking, the same. In our case, superstars cannot provide the service alone. Soccer stars are part of teams and receive certain salary payments, bonuses or signing fees that do no longer necessarily correspond to their market potential. The predetermined (base) salary, for example, does not increase if the player exhibits excellent field performance. Bonus payments are typically contingent on a large set of confidential terms and conditions. Signing fees or transfer values depend (among other factors) on the bargaining power of the buying and selling club. Thus, market values should better reflect the value generation potential of a player than pure salaries. The Kicker market value proxies incorporate not only salaries but also signing fees, bonuses, transfer fees, and possibly even a remaining producer surplus. However, the market value proxies do not include individual endorsement fees.

[Figure 1 about here]

Figure 1 reveals a rather normally distributed density function for the $\log 10$ of market values. In line with Rosen (1981), we define superstars as the players at the top end of the market value distribution. As Rosen (1981) does not state whether the $2 \%, 5 \%$ or $10 \%$ most valuable players are defined as superstars, we run different quantile regressions that describe different points at the top end of the distribution. While the median player is valued at $€ 1.25$ million, star players at the $95 \%$ quantile are exchanged for $€ 5.5$ million (see Table 3 ). $75 \%$ of the players in the highest German soccer league have a market value of one million Euros and above. Table 3 illustrates the market values at different quantiles.

[Table 3 about here]

For the empirical model, we use the natural logarithm of the market values expressed in Euros and adjusted for inflation. During the considered time frame (2001 until 2005), the players' market values have remained rather stationary in German soccer. 


\section{Control Variables}

Besides the indicators of individual talent and popularity described in sections IV and $\mathrm{V}$, we also use several control variables to eliminate alternative explanations, such as age, experience, tactical position, and team effects. An overview of all variables is given in Table 4. Since several studies (e.g., Lucifora and Simmons 2003; Torgler and Schmidt 2007) show that a soccer player's age has a positive but diminishing impact on salaries, we control for age and age squared. In addition, we hold the number of present and past appearances in the highest German league constant to account for the experience of a player. ${ }^{14}$ Furthermore, we incorporate team dummies, as (unobserved) team heterogeneity may exert a significant influence on a player's market value (Idson and Kahane 2000). Somebody who is on the squad of the team that wins the championship enjoys much greater publicity and financial rewards than someone on a team that is relegated to the next lower league. Position dummies are used to control for specific effects resulting from the tactical position of a player. Lehmann and Weigand (1999) find evidence that midfielders earn significantly more money than players in other tactical positions. ${ }^{15}$

Since the Kicker soccer magazine publishes the estimated market values at the beginning of a new season, we use the values of the next season as dependent variable. This implies that we have missing observations for the dependent variable whenever a player leaves the league because Kicker estimates the market values only for the players engaged by a top-division German team. If so-called sample attrition is driven by unobservable factors that also influence the dependent variable in the main equation, our estimates may be distorted by selection bias. Thus, the validity of the results largely depends on whether the attrition status is random after conditioning on a vector of covariates. In the following, we want to test this requirement.

${ }^{14}$ We also tested for a possible influence of the contractual status of the player by introducing a dummy variable denoted as 1 if the contract ends at the end of the season and a second dummy variable denoted as 1 if the player contract ends at the end of the next season. However, none of the controls had a significant impact on market values nor changed the other coefficients in any significant way. The relationship between a player's contract duration and his market value is controversial: some scholars, like Lehn (1982) and Scoggins (1993), conjecture that guaranteed multi-year contracts reduce player performance due to a moral-hazard effect, while others like Kahn (1993) and Maxcy (2004) argue that only the better players receive comparably long contracts (positive self-selection effect).

${ }^{15}$ Whereas the positional dummies just control for different salary levels depending on the tactical position of a player, we allow for different talent and popularity effects to be experienced by offensive and defensive star players in the third sensitivity analysis in section VII. 
Let us denote $A_{i t}$ as an attrition dummy equal to 1 if the observation is missing its value of $y_{i t}$ due to attrition and 0 if not. Then, selection bias occurs if the probability function of $A_{i t}$ conditional on the dependent variable and the regressors is not equal to the probability function conditional on the regressors alone (Fitzgerald, Gottschalk, and Moffitt 1998). Thus:

$$
\operatorname{Pr}\left(A_{i t}=0 \mid y_{i t}, x_{i t}^{\prime}\right) \neq \operatorname{Pr}\left(A_{i t}=0 \mid x_{i t}^{\prime}\right) .
$$

As $y_{i t}$ is not observable if $A_{i t}=1$, equation 3 cannot be tested directly. However, with panel data, we can use the individual means of the dependent variable (see also Fitzgerald et al. 1998). Hence, potential selection bias is tested by estimating a probit equation of a nonresponse in season $t$ conditional on the individual means of the dependent variable $\left(\overline{y_{i t}}\right)$ and conditional on observable factors $x_{i t}^{\prime}$. If the coefficient of $\overline{y_{i t}}$ is significantly different from zero, the assumption of "selection on observables" will no longer be satisfied. We estimate:

$$
\operatorname{Pr}\left(A_{i t}=1\right)=\alpha+\beta \overline{y_{i t}}+\chi x_{i t}^{\prime}+\varepsilon_{i t},
$$

where $x_{i t}^{\prime}$ is a vector of covariates. In addition to the variables measuring a player's talent, popularity and various controls, we also include a dummy variable RELEGATION that equals 1 if the player's team is demoted and 0 otherwise. In German soccer, the weakest three teams, including most of the squad members, are relegated to the next lower league and, therefore, drop out of the sample. Estimating equation 4 , we find that $\beta=-0.04$ is not statistically different form zero $(p$-value $=0.15)$. The probit regression results (illustrated in Table 11 in the appendix) additionally show that players engaged in relegated teams have a significantly higher likelihood of dropping out of the sample. Hence, we draw two conclusions. First, we must introduce the relegation dummy into the main regression because this affects selection beyond the talent and popularity variables of a player. Second, after introducing this additional control variable, attrition is no longer selective on the individual specific means of the dependent variable. Furthermore, potential remaining negative selectivity is appeased by the fact that we specifically concentrate on star players at the upper quantiles, who are unlikely to leave the league given the (insignificant) negative coefficient $\beta$ in equation 4 . Table 4 illustrates the descriptive statistics of the variables we use for the market value regressions. 


\section{Identification Strategy}

A standard approach is to specify the unknown parameters of a linear regression using the method of OLS or least absolute deviation (LAD). Both methods lead to an approximation to the mean (OLS) or median (LAD) and represent the "central" tendency of a conditional distribution. However, they tell little about tail behavior. The OLS procedure will therefore not be able to capture the superstar phenomenon correctly. The quantile regression approach, originally developed by Koenker and Bassett (1978), allows one to characterize a particular point in the conditional (asymmetric) distribution. It minimizes an asymmetrically weighted sum of absolute errors where the weights are functions of the quantile of interest $(\theta)$ :

$$
\min _{\beta} \frac{1}{n}\left\{\sum_{i: y_{i t} \geq x_{i t}^{\prime} \beta} \theta\left|y_{i t}-x_{i t}^{\prime} \beta\right|+\sum_{i: y_{i t} \leq x_{i t}^{\prime} \beta}(1-\theta)\left|y_{i t}-x_{i t}^{\prime} \beta\right|\right\} .
$$

The application of quantile methods to panel data is not unproblematic (Koenker 2004). Whereas, in the linear regression model, fixed effects methods can account for the constant unobserved heterogeneity of a player as a linear intercept, quantile regressions require a constant distributional individual effect. If the number of time periods is high and the number of cross-sectional observations is low, the estimation of such a distributional individual effect is possible by including cross-sectional dummies (Koenker 2004). In our setting, however, the inclusion of player dummies would clearly lead to the incidental parameters problem, as we have a large number of cross-sectional observations and only one to five time periods. We therefore use a pooled regression approach to estimate the conditional distribution of the dependent variable. As the observations of the same player are unlikely to be independent, the standard asymptotic-variance formula (Koenker and Basset 1978) and the standard bootstrap approach to estimating standard errors cannot be applied. Instead, a given bootstrap sample is created by repeatedly drawing (with replacements) the same player from the sample of players. In doing so, we allow for serial error correlation between the observations of the same player. As we run 1000 bootstrap replications, the estimates of the robust standard errors are rather stable (Koenker and Hallock 2000). 


\section{$\underline{\text { Results }}$}

Table 5 illustrates the estimation results. Besides three different quantile regressions, we also present the pooled OLS estimates, as well as the results of a player fixed effects regression for the purpose of comparison.

[Table 5 about here]

We find clear evidence that both a player's talent and his non-performance-related popularity increase his market value. This finding is robust across all specifications. Regarding the talent indicators, we see that the number of goals; the number of clearances, blocks, and interceptions; and the saves to shots ratio significantly increase the star's market value in all considered quantiles.

If a star player at the $95 \%$ quantile scores one more goal per season, his market value increases by $4.5 \%$. The coefficients in the quantile regressions are similar in magnitude to those in the OLS or fixed effects specification. Thus, the relative marginal effects are more or less constant. The absolute size of the marginal talent effect is magnified, however, as we move up the market value distribution. ${ }^{16}$ An additional goal scored by a superstar at the $95 \%$ quantile, for example, increases his market value by $€ 0.25$ million $(0.045 * 5.5$ million), whereas the absolute increase of an additional goal scored by an average player is worth only $€ 0.06$ million $(0.040 * 1.5$ million). If a mediocre goalkeeper improves his saves to shots ratio by $1 \%$, his market value increases by $€ 0.006$ million $(0.01 * 0.37 * 1.5$ million). A $1 \%$ improvement on the part of a star goalkeeper, however, leads to an increase of $€ 0.027$ million $(0.01 * 0.49 * 5.5$ million $) .{ }^{17}$ At first glance, these findings seem weird, as it should not matter who scores the goals or prevents the opposition team from scoring. Going back to the superstar theory of Rosen (1981), the magnification effect can be explained by the imperfect substitutability of higher and lower talent. Thus, from the consumer's perspective, one player scoring 10 goals is not the same as ten players scoring one goal each. This implies that

\footnotetext{
${ }^{16}$ The magnification does not apply to the popularity effect, however, as we measure a player's popularity with the logarithm of the non-performance-related press citations. Hence, the popularity coefficient has to be interpreted as elasticity. Adler (1985) does not necessarily assume a convex relationship between a star's salary and popularity.

${ }^{17}$ The magnitudes of the effects prove plausible when analyzing team revenues and revenue performance sensitivity in German soccer (see second robustness analysis in section VII).
} 
additional talent is magnified into larger earning differences at the top end of the scale than at the bottom end. We have to be cautious, however, with generalizations regarding the exact magnitudes of the quantile effects: a player who happens to be in a specific quantile of a conditional distribution will not necessarily find himself in the same quantile if his independent variables change (Buchinsky 1998).

Whenever correlational designs are used, concerns about internal validity such as possible reverse causality may be raised. The issue of reverse causality (impact of market values on talent or popularity) is, however, appeased by the lag structure of our model. The independent variables are determined during the season, whereas the dependent variable is estimated at the end of the past season prior to a new season. The market values should therefore be influenced by the player's talent and popularity and not vice versa. Since we have a typical microeconomic dataset with a large cross-sectional dimension and a small time dimension, adaptions of Granger causality tests to panel data, for example those formulated by Holtz-Eakin, Newey, and Rosen (1988), are not suitable in our context. Granger causality is an intrinsically dynamic concept (Attanasio, Picci, and Scorcu 2000).

\section{SENSITIVITY ANALYSES}

In this section, we perform three different sensitivity analyses. First, we test the robustness of the results if the market value proxies of a second independent source are used. Secondly, we examine the plausibility of the talent coefficients by relating field performance to the team's winning percentage and the winning percentage to the team's revenue. Thirdly, we explore whether talent and popularity effects are different depending on the tactical position of a player.

\section{Different Data Source of the Players' Market Values}

At the end of the 2004/05 season, we collected a cross-sectional sample of market value estimates of all players who appeared in the season for at least half an hour (in total, 427 players) from www.transfermarkt.de. As Transfermarkt does not provide archive data, market values of players in earlier or later seasons were unfortunately not available. As with the Kicker market values, the market values from Transfermarkt are estimated by industry experts and include not only salaries but also signing fees, bonuses and transfer fees. Table 6 
shows that the significantly positive talent and popularity effects remain robust when taking www.transfermarkt.de as the data source for the dependent variable. The coefficients are slightly higher than in the Kicker panel sample, but the general empirical findings of the last section are confirmed throughout. Thus, our results are not driven by peculiarities of the Kicker proxies.

[Table 6 about here]

\section{$\underline{\text { Revenue Performance Sensitivity }}$}

The basic unit of competition in our context is the team. The star's talent is valuable to the team because it increases the team's winning percentage, which in turn is positively associated with the team's revenue potential. As we have access to detailed revenue data for the German soccer teams, ${ }^{18}$ we want to test the plausibility of the returns to talent in the previous section by estimating revenue performance sensitivity at the team level. In doing so, we follow a procedure outlined by Scully (1974). He suggested first calculating the effect of different field performance measures on the team's winning percentage and then considering the impact of the team's winning percentage on team revenues. In line with Scully (1974), we do not examine the influence of popularity on team revenues because, unlike with talent, there is no clear measure of team-level popularity. It is unclear how individual publicity should be aggregated at the team level.

In our first step, we relate the team's winning percentage to the talent indicators as described in Table 4 but aggregated at the team level. Running a team fixed effects regression including all teams appearing in the highest German soccer league between 2001/02 and 2005/06 (90 observations and 24 different teams), we find significantly positive coefficients for the number of goals scored (coef. $=0.0067$, std.error $=0.0013$ ) and the saves to shots ratio (coef. $=0.6493$, std.error $=0.1212) .{ }^{19}$ No other performance measures have a distinct influence on the team's winning percentage. In a second step, we use proprietary team revenue data and relate the revenue to the team's winning percentage. The underlying hypothesis is that fan

\footnotetext{
${ }^{18}$ This data has been provided by courtesy of René Algesheimer, Leif Brandes, and Egon Franck. For a first empirical analysis of this data, see Algesheimer, Brandes, and Franck (2009).

${ }^{19}$ Detailed regression results are illustrated in Table 12 in the appendix. This regression differs from the team production estimation in section IV because it employs seasonal (not match-level) data and a different set of explanatory variables.
} 
interest and hence revenue is positively affected by team wins (Scully 1974). Since the clubs usually renegotiate sponsoring and broadcasting contracts at the beginning of the season, we use the winning percentage of the last season as the explanatory variable. Even match day revenue is largely influenced by the previous season's percentage of wins because season ticket holders represent around 55\% of total match attendees (Bundesliga Report 2009). A further argument regarding why we use the winning percentage from the last season relates to the very lucrative UEFA Champions League (CL). The top two clubs from the last season qualify for the CL and the third-place club from the last season is eligible for the CL qualifying round, which provides substantial extra money in the current season. ${ }^{20}$ Of course, a team's revenue is driven not only by sportive success but also by other factors such as the size of the market, the team's (non-performance-related) star attraction, or stadium capacity. By estimating a team fixed effects model, we control for all team aspects that are likely to be time-constant - for example, the team's market potential. Furthermore, we explicitly control for the team's stadium capacity (measured in 1000s) because it may change substantially over time due to stadium reconstruction. Previous studies found that stadium capacity significantly influences (gate) revenues (e.g., Berri et al. 2004; Brandes et al. 2008). We run separate models for total revenue and for the subcategories of match day revenue, sponsoring revenue, broadcasting revenue and the revenue from various sources such as transfer fees, rental income, and catering and merchandizing income.

\section{[Table 7 about here]}

Table 7 reveals that a $1 \%$ increase in the team's winning percentage increases total revenues by $1.18 \%$. The highest revenue performance sensitivities are found (in a decreasing order) for broadcasting revenue (175\%), match day revenue (163\%) and sponsoring revenue (137\%). Stadium capacity clearly affects the team's match day revenue but has no significant impact on other revenue categories such as sponsoring or broadcasting revenues. Following Scully (1974), we approximate the marginal revenue product of goal scoring and the saves to shots ratio by multiplying the coefficients of the team production function by the coefficients of the revenue function. As the coefficients of the latter are determined in a log-level model,

\footnotetext{
${ }^{20}$ In the season 2004/05, the clubs that qualified for the CL received $€ 414.1$ million in additional broadcasting income and generated substantial extra match day turnover.
} 
we multiply the product by the average revenue of a team. Thus, the average marginal revenue product for one additional goal scored is 0.0067 multiplied by 1.18 multiplied by the average team revenue (€66.2 million), which equals $€ 0.52$ million. Similarly, we can derive the marginal revenue product if the goalkeeper's saves to shots ratio improves by $1 \%$. In doing so, we achieve a marginal revenue product of $€ 0.51$ million $(0.01 * 0.6493 * 1.18 * 66.2$ million). From the market value regressions in section VI, we know that one additional goal scored increases the star's market value by $€ 0.25$ million, and that a $1 \%$ improvement in the saves to shots ratio of a star goalkeeper increases his market value by $€ 0.03$ million. Hence, even though the marginal effects of the talent variables on the star's market value seem to be rather large, they are still substantially lower than the (average) marginal revenue products of the same variables. Especially the contributions of goalkeepers seem to be undervalued, a finding already shown by Frick (2007). It is dangerous, however, to put much emphasis on the exact magnitudes of the effects because they react sensitively to the chosen estimation strategy and the explanatory variables included. We know, for example, that not only goal scoring and the saves to shots ratio matter for winning, but that their strong influence may hide the effects of other important field performance measures such as clearances, blocks, and interceptions and shots on target, to mention just some examples. Thus, the marginal revenue products of goal scoring and of the saves to shots ratio tend to be overestimated, as they also incorporate the positive aspects of other important performance characteristics that influence winning. Nevertheless, we can still say that the large impact of a player's talent on his market demand seems to be justified given the high revenue potential and the significant revenue performance sensitivity in the highest German soccer league.

\section{Tactical Positions and an Alternative Talent Measure}

Soccer is a very interactive game, with high mutual interaction among all players on the field. There is no clear distinction between offense and defense, as in baseball, and the players' roles are less narrowly circumscribed than in (American) football. However, soccer players are still assigned to a certain tactical position. Besides the specific task of the goalkeeper as the ultimate defender of the team, the ten outfield players are generally categorized as defenders, midfielders and attackers. Whereas the main task of the offensive players (attackers and midfielders) is goal scoring, defensive players (goalkeepers and defenders) should primarily prevent goals scored by the opposition team, although even goalkeepers score goals and attackers clear the ball at the own goal line once in a while. So 
far, we have assumed a uniform relationship between the different performance categories and the market values for all tactical positions. However, it is likely that not all talent indicators are equally important for the different tactical positions. In the following, we run separate regressions for offensive and defensive players in order to allow for tactical-specific slope coefficients among the performance variables. In the subsample including only the offensive players (attackers and defenders), we exclude the variables characterizing typical defense qualities (clearances, blocks, and interceptions, as well as the saves to shots ratio), whereas the offensive talent measures (goals, assists, shots on target, shots off target) are excluded when analyzing the goalkeepers and defenders. Otherwise, we employ the same variables and econometric approaches as before. Table 8 illustrates the estimation results of the OLS specification and the $95 \%$ quantile regression.

[Table 8 about here]

The first two columns in Table 8 reveal that both talent and popularity clearly increase the market values of offensive players. The number of goals and assists scored, as well as the popularity measure, exerts a significant positive influence. The talent indicators display high joint significance. The magnitudes of the effects are very similar to the results in Table 5, perhaps with one exception: receiving a red card, which is expected to decrease a star's market value, in fact increases the market demand of offensive star players.

The two columns on the right in Table 8 show that the talent indicators are no longer jointly significant when one is analyzing only defenders and goalkeepers, whereas the popularity effect is comparably higher in defense than for offense. Is talent irrelevant for stars playing defense? We doubt it. We rather assume that the performance of forwards is more visible and better measureable than the contributions of defensive players whose task is fuzzier and thus more difficult to capture. Even though the Opta statistics are very precise, they represent a quantitative rather than qualitative point of view, ignoring blurry aspects like good position play, creativity of play or key player attitudes. Reinstein and Snyder (2005) argue that expert opinions may serve as important "product" information revealing otherwise uncertain quality aspects. We therefore test expert appraisals as a different approach to measuring a player's talent. The overall match performance of each player who plays more than half an hour in the highest German soccer league is consistently evaluated and marked 
by sports experts, using the German grading scale that varies between 1.0 (excellent) and 6.0 (very bad). The individual match evaluations are published on the webpage www.kicker.de. ${ }^{21}$ We collected all match evaluations for all players appearing in the highest German soccer league during the considered time frame (2001/02 to 2005/06). For ease of interpretation, we transformed the original marks by subtracting the original mark from 7. A player's talent, then, is defined by the average mark a player receives during a season. In Table 9, we replace the quantitative performance statistics with more qualitative expert evaluations.

[Table 9 about here]

Using expert evaluations as a talent indicator, we again find strong influences of both talent and popularity, regardless of whether offensive or defensive players are analyzed. Looking at the magnitudes of the effects, we notice that defensive players have comparably higher returns to popularity and lower returns to talent than do offensive (star) players. ${ }^{22}$

\section{DISCUSSION}

An empirical validation of the different superstar theories proposed by Rosen (1981) and Adler (1985) requires valid and quantifiable talent measures. This paper argues that tournaments in professional sports help to determine the (relative) talent of an athlete, which is otherwise unobserved and therefore hard to identify. The label of "winner" does not entail a subjective impression, but rather results from a clearly defined competition in a controlled environment. In team production settings, in which teams and not individuals compete against each other, the situation is a little more complicated. In this case, a player's talent is considered his contribution to the team output. Thus, we first estimated a team production function to detect critical playing elements impacting team success, which are taken as talent indicators in the market value regression. A player's non-performance-related popularity is

${ }^{21}$ If the experts really gave harsher ratings to stars than to non-stars, as some people believe, the playing talent of stars would be underestimated using the Kicker expert evaluations. We also have to be aware of potential single source bias.

${ }^{22}$ As the function relating a player's talent and popularity to market values could involve non-additive patterns, we also tested for interaction effects. The interaction term between expert evaluations as talent proxy and the non-performance-related press citations as a popularity indicator was insignificant in all specifications, however. 
defined by the residuals of a regression of the logarithm of individual press citations relating to the player's performance. Running different quantile regressions, we find evidence that both talent and non-performance-related popularity contribute to the market value differentials in the highest German soccer league. Since the market value proxies we used do not include individual endorsement fees, our estimates may be considered as lower bounds. Endorsement fees usually react very sensitively to the athlete's talent and popularity.

A robustness analysis reveals that the impacts of talent and popularity are robust when using a different source of market value proxies and that the effects apply to both offensive and defensive star players. In the case of the offense, slightly higher returns to talent are found than for the defense, whereas the marginal impact of popularity is comparably higher in the case of the defense than that of the offense. This finding could indicate that the talent effect is higher when quality can be ascertained more easily, and that non-performancerelated popularity is comparably more important for remuneration if quality is more difficult to identify and measure. A similar result was found by Wang (2008), who showed that scoring performance was more highly rewarded in the NBA than non-scoring performance even though the contributions of scoring and non-scoring performance to the team's winning percentage are similar. In addition, we find that the estimated talent coefficients are plausible given the high revenue potential and the significant revenue performance sensitivity of German soccer teams.

Of course, further work is required to test the generalizability of our results. A more indepth examination of the factors determining the consumer's decision to buy access to a superstar service would be very beneficial. In this paper, we considered (Rosen-style) talent as the individual's ability to impact the likelihood of winning a sports competition. In contrast, all non-sportive factors, like celebrity status in the media, were seen as aspects of (Adler-style) popularity that also attract fans with something more to consider than the pure quality of the game. Adler (1985) sees star popularity as a way of economizing on the costs of accumulating consumption capital, which itself increases the perceived quality of the star's service. In this paper, we directly relate the demand for a star's services to the star's popularity and neglect consumption capital as the theoretical link. However, the relevance and conception of consumption capital definitely deserves the future attention of both theorists and empiricists. 
Even though the economic concept of superstars was first developed to describe the enormous salaries of individual service providers in the entertainment industries, ${ }^{23}$ skewed earning distributions can be found in many work contexts, the most prominent of which is the area of top management compensation. Although we have not specifically addressed the issue of "management stars" in our paper, the set-up and framing of our approach could provide input for the specific body of literature on the drivers of top management salaries. Our study analyzes an individualistic phenomenon (the determinants of a star player's remuneration) in an institutional setting in which teams and not individuals are the basic unit of competition. This, of course, complicates the identification of an individual's contribution to the team output. On the other hand, this team production context captures a basic element of managerial work, as the superstars in management also emerge from a team production setting, where firms and not individuals are the relevant units of competition in markets.

In 1982, Sherwin Rosen expanded his superstar theory to managerial reward distributions across ranks in and among hierarchical firms. He argues that the enormous salaries of CEOs are justified if the (superior) abilities of CEOs filter through the entire corporation via a chain of command technology and may therefore increase firm productivity by more than the amount of their abilities. Empirical studies, however, contest a pure Rosentype explanation of CEO salaries: Bertrand and Mullainathan (2001) show that CEOs are paid not only for their performance but also based on luck, which means that CEOs receive pay premiums associated with profit increases that are entirely generated by external factors such as changes in oil prices and exchange rates. Further empirical studies find considerable "popularity" effects: Lee (2006) shows that the press coverage of a CEO increases his/her salary even after controlling for the firm's performance. Malmendier and Tate (forthcoming) and Wade, Porac, Pollock, and Graffin (2006) relate a CEO's reputation to the CEO's compensation and subsequent firm performance. Both papers find that CEOs receive higher remuneration after winning a prestigious business award and that the ex-post consequences for firm performance are negative. Hence, superstar CEOs tend to be paid not only for their managerial ability but for other factors beyond performance as well. Furthermore, the correlations between a star manager's talent and popularity and between firm performance and popularity are, unlike in professional sports, not necessarily positive but indeed often negative. Celebrity CEOs may indulge in activities that provide little firm value, such as

\footnotetext{
${ }^{23}$ Rosen (1981) uses examples of full-time comedians and classical musicians, and Alder (1985) mentions singing and painting as artistic activities generating superstars.
} 
writing books, sitting on outside boards or playing golf (Malmendier and Tate forthcoming). Also CEOs receiving great media praise may become overconfident about the efficiency of their past actions and future abilities (Hayward, Rindova, and Pollock 2004). Hayward and Hambrick (1997) show that CEOs who enjoyed high press publicity paid larger premiums for acquisitions due to CEO hubris.

Even though both talent and popularity effects seem highly relevant for top management compensation, the specific literature mostly fails to make a clear distinction between the two effects, probably because valid and measurable indicators of managerial ability are hard to find. Our paper suggests that future empirical research on top management compensation should first try to proxy managerial ability by estimating a firm production function before other drivers of CEO salaries like popularity can be properly isolated.

\section{REFERENCES}

Adler, M. "Stardom and talent." American Economic Review, 75(1), 1985, 208-12.

Adler, M. "Stardom and talent," in Handbook of Economics of Art and Culture, edited by V. Ginsburgh and D. Throsby Amsterdam: Elsevier, 2006, 895-906.

Algesheimer, R., Brandes, L., Franck, E. "It's all about behavior: How financial investments translate into firm success.“ Working paper, University of Zürich, 2009.

Attanasio, O. P., Picci, L., and Scorcu, A. E. "Saving, growth, and investment: a macroeconomic analysis using a panel of countries." The Review of Economics and Statistics, 82, 2000, 182-211.

Berri, D. J. "Who is 'most valuable'? Measuring the player's production of wins in the National Basketball Association." Managerial and Decision Economics, 20, 1999, 41127.

Berri, D. J., Schmidt, M. B. and Brook, S. L. "Stars at the gate. The impact of star power on NBA gate revenues." Journal of Sports Economics, 5, 2004, 33-50.

Bertrand, M. and Mullainathan, S. "Are CEOs rewarded for Luck? The ones without principals are." Quarterly Journal of Economics, 116, 2001, 901-932

Blass, A. A. "Does the Baseball labor market contradict the human capital model of investment?" The Review of Economics and Statistics, 74(2), 1992, 261-68. 
Borghans, L. and L. Groot. "Superstardom and monopolistic power: why media stars earn more than their marginal contribution to welfare." Journal of Institutional and Theoretical Economics, 154(3), 1998, 546-72.

Brandes, L., Franck, E. and Nüesch, S. "Local heroes and superstars - An empirical analysis of star attraction in German soccer.” Journal of Sports Economics, 9(3), 2008, 266-286.

Buchinsky, M. "Recent advances in quantile regression models: a practical guide for empirical research." Journal of Human Resources, 33, 1998, 88-126.

Bundesliga Report 2009. "Die Bundesliga. Menschen begeistern [The Bundesliga. Inspiring people]. Frankfurt am Main.

Carmichael, F., D. Thomas and R. Ward. "Team performance: the case of English premiership football.” Managerial and Decision Economics, 21(1), 2000, 31-45.

Chung, K. H. and R. A. K. Cox. "A stochastic model of superstardom: an application of the Yule distribution." Review of Economics and Statistics, 76(4), 1994, 771-75.

Connolly, M. and A. B. Krueger. "Rockonomics: the economics of popular music." in Handbook of Economics of Art and Culture, edited by V. Ginsburgh and D. Throsby. Amsterdam: Elsevier, 2006, 667-719.

Crain, W. M. and R. D. Tollison. "Consumer choice and the popular music industry: a test of the superstar theory." Empirica, 29(1), 2002, 1-9.

Farrell, J. and G. Saloner. "Standardization, compatibility, and innovation." Rand Journal of Economics, 16(1), 1985, 70-83.

Fitzgerald, J., Gottschalk, P., and Moffitt, R. "An analysis of sample attrition in panel data. The Michigan Panel Study of Income Dynamics." Journal of Human Resources, 33, 1998, 251-299.

Franck, E. and S. Nüesch. "Mechanisms of Superstar Formation in German Soccer: Empirical Evidence.” European Sport Management Quarterly, 8(2), 2008, 145-164.

Frank, R. H. and P. J. Cook. The winner-take-all society. New York: The Free Press, 1995.

Frey, B. S. "Superstar museums. An economic analysis." Journal of Cultural Economics, 22, $1998,113-25$.

Frick, B. "Die Einkommen von "Superstars" und "Wasserträgern" im professionellen Teamsport” [The incomes of „superstars“ and „,benchwarmers“ in professional team sports]." Zeitschrift für Betriebswirtschaft, 71(6), 2001, 701-20.

Frick, B. "Contest theory and sport." Oxford Review of Economic Policy, 19(4), 2003, 51229. 
Frick, B. "The football player's labor market: Empirical evidence from the major European leagues." Scottish Journal of Political Economy, 54(3), 2007, 422-446.

Eschweiler, M. and Vieth, M. "Preisdeterminanten bei Spielertransfers in der FußballBundesliga." [Determinants of the players' market values in the German soccer league] Zeitschrift für Betriebswirtschaft, 64, 2004, 671-692.

Giles, D. E. "Superstardom in the US popular music industry revisited." Economics Letters, 92(1), 2006, 68-74.

Haas, D., Kocher, M. G., and Sutter, M. "Measuring efficiency of German football teams by data envelopment analysis." Central European Journal of Operation Research, 12, 2004, 251-268.

Hamlen, W. "Superstardom in popular music: empirical evidence." Review of Economics and Statistics, 73(4), 1991, 729-33.

Hamlen, W. "Variety in superstardom in popular music." Economic Inquiry, 32, 1994, 395406.

Hausman, J. A. and G. K. Leonard. "Superstars in the National Basketball Association: economic value and policy.” Journal of Labor Economics, 15(4), 1997, 586-624.

Hayward, M. L. A. and Hambrick, D. C. "Explaining the premiums paid for large acquisitions: Evidence of CEO hubris." Administrative Science Quarterly, 42, 1997, 103-127.

Hayward, M. L. A., Rindova, V. P., and Pollock, T. G. "Believing one's own press: the causes and consequences of CEO celebrity", Strategic Management Journal, 25, 2004, 637-653.

Holtz-Eakin, D., Newey, W., and Rosen, H. S. "Estimating vector autoregressions with panel data", Econometrica, 56(6), 1988, 1371-95

Hübl, L. and Swieter, D. "Der Spielermarkt in der Fußball-Bundesliga [The player market in the German soccer league]." Zeitschrift für Betriebswirtschaft, 72, 2002, 105-123.

Idson, T. L. and L. H. Kahane. "Team effects on compensation. An application to salary determination in the National Hockey League." Economic Inquiry, 38, 2000, 345-57.

Kahn, L. M. "Free agency, long-term contracts and compensation in Major League Baseball: estimates from panel data." Review of Economics and Statistics, 75(1), 1993, 157-64.

Katz, M. L. and C. Shapiro. "Network externalities, competition, and compatibility." The American Economic Review, 75(3), 1985, 424-40. 
Kern, M. and B. Süssmuth. "Managerial efficiency in German top league soccer: an econometric analysis of club performances on and off the pitch." German Economic Review, 6(4), 2005, 485-506.

Koenker, R. and G. Bassett. "Quantile regression.” Econometrica, 46(1), 1978, 33-50.

Koenker, R. and K. F. Hallock. "Quantile regression. An introduction." Working paper, University of Illinois at Urbana-Champaign, 2000.

Koenker, R. “Quantile regression for longitudinal data”. Working paper, 2004.

Kremer, M. "The O-ring theory of economic development." Quarterly Journal of Economics, 108(3), 1993, 551-75.

Krueger, A. B. "The economics of real superstars: the market for rock concerts in the material world." Journal of Labor Economics, 23, 2005, 1-30.

Lee, S. "CEO reputation: who benefits - the firm or the CEO?" Working paper, University of Southern California, 2006.

Lehmann, E. and J. Weigand. "Determinanten der Entlohnung von Profifussballspielern Eine empirische Analyse für die deutsche Bundesliga [Wage determination among professional soccer players - evidence from the German league]." Betriebswirtschaftliche Forschung und Praxis, 51, 1999, 124-35.

Lehmann, E. and G. G. Schulze. "What does it take to be a star? - The role of performance and the media for German soccer players." Applied Economics Quarterly, 54(1), 2008, $59-70$.

Lehn, K. "Property rights, risk sharing, and player disability in Major League Baseball." Journal of Law and Economics, 25(2), 1982, 347-66.

Lucifora, C. and R. Simmons. "Superstar effects in sport. Evidence from Italian soccer." Journal of Sports Economics, 4(1), 2003, 35-55.

Malmendier, E. and Tate, G. "Superstar CEOs." Quarterly Journal of Economics, forthcoming.

Marshall, A. Principles of Economics. $8^{\text {th }}$ ed., 1947, New York: MacMillan.

MacDonald, G. D. "The economics of rising stars." American Economic Review, 78(1), 1988, $155-66$

Maxcy, J. "Motivating long-term employment contracts: risk management in Major League Baseball." Managerial Decision and Economics, 25(2), 2004, 109-20.

Mullin, C. J. and Dunn, L. F. "Using baseball card prices to measure star quality and monopsony." Economic Inquiry, 40(4), 2002, 620-632. 
Reinstein, D. A. and C. M. Snyder. "The influence of expert reviews on consumer demand for experience goods: a case of study of movie critics." The Journal of Industrial Economics, 53(1), 2005, 27-51.

Rosen, S. "The economics of superstars." American Economic Review, 71(5), 1981, 845-58.

Salganik, M. J., P. S. Dodds, and D. J. Watts. "Experimental study of inequality and unpredictability in an artificial cultural market." Science, 311(5762), 2006, 854-56.

Schmidt, S. L., Torgler, B., and Frey, B. S. "Die Auswirkung von Neid auf individuelle Leistungen: Ergebnisse einer Panelanalyse [Consequences of envy on individual performance: evidence from a panel analysis]." Zeitschrift für Betriebswirtschaft, 79, 2009, 303-334.

Schulze, G. G. "Superstars." in The Handbook of Cultural Economics, edited by R. Towse. Cheltenham: Edward Elgar, 2003, 431-36.

Scoggins, J. F. "Shirking or stochastic productivity in Major League Baseball: comment." Southern Economic Journal, 60(1), 1993, 239-40.

Scully, G. W. "Pay and performance in Major League Baseball." The American Economic Review, 64(6), 1974, 915-30.

Simon, H. A. "On a class of skew distribution functions." Biometrika, 42(1), 1955, 425-40.

Throsby, D. "The production and consumption of the arts: a view of cultural economics." Journal of Economic Literature, 32(1), 1994, 1-29.

Torgler, B., Schmidt, S. L. "What shapes player performance in soccer? Empirical Findings from a panel analysis." Applied Economics, 39, 2007, 2355-2369.

Torgler, B., Schaffner, M., Schmidt, S. L., and Frey, B. "Do employees care about their relative position? Behavioural Evidence focusing on performance." Center for Research in Economics, Working paper, 2008.

Wade, J. B., Porac, J. F., Poolock, T. G., and Graffin, S. D. "The burden of celebrity: The impact of CEO certification contests on CEO pay and performance." Academy of Management Journal, 49, 2006, 643-660.

Wang, L. "Money and fame: vividness effects in the National Basketball Association." Journal of Behavioral Decision Making, 22, 2008, 20-44.

Wooldridge, J. M. "Introductory econometrics. A modern approach". Thomson SouthWestern: Mason. 2003.

Yule, G. U. "A mathematical theory of evolution." Philosophical Transactions of the Royal Society, 213, 1924, 21-87. 
Zak, T. A., C. J. Huang and J. J. Siegfried. "Production efficiency: The case of professional basketball." Journal of Business, 52(3), 1979, 379-92. 
TABLE 1

Variables and Descriptive Statistics of the Team Production Function

\section{Dependent variable}

Goal difference

\section{Independent variables}

\section{Attacking plays}

Difference in shots on target

Difference in shots off target

Difference in shots hitting (goal net) woodwork

Difference in clearances, blocks and interceptions

Difference in saves to shots ratio by the goalkeeper

Difference in number of times the ball was caught by the goalkeeper

Difference in number of times the ball was dropped by the goalkeeper

\section{Efficiency plays}

Difference in \% successful passes

Difference in \% successful flicks

Difference in \% successful crossings

Difference in \% successful dribblings

Difference in \% successful tackles

\section{Aggressive plays}

Difference in number of red cards

Difference in number of yellow cards

Difference in fouls conceded in one's own third of the playing area

Difference in fouls conceded not in one's own third of the playing area

Difference in penalties conceded (fouls conceded in penalty area)

Difference in hands conceded

\section{Defensive plays}

$\begin{array}{llll}-0.014 & 1.817 & -6 & 6\end{array}$

$\begin{array}{rrrr}-0.044 & 3.073 & -11 & 11 \\ -0.051 & 4.464 & -13 & 15 \\ -0.012 & 0.748 & -3 & 5 \\ & & & \\ -0.154 & 19.674 & -67 & 67 \\ -0.003 & 0.362 & -1 & 1 \\ -0.065 & 2.469 & -9 & 9 \\ -0.005 & 0.457 & -2 & 3 \\ & & & \\ 0.000 & 0.081 & -0.27 & 0.3 \\ -0.002 & 0.296 & -1 & 1 \\ 0.000 & 0.142 & -0.48 & 0.52 \\ -0.004 & 0.154 & -0.85 & 0.76 \\ -0.006 & 0.130 & -0.41 & 0.47\end{array}$

$\begin{array}{rrrr}0.001 & 0.445 & -2 & 2 \\ 0.031 & 1.700 & -7 & 6 \\ -0.070 & 2.646 & -10 & 11 \\ 0.215 & 6.138 & -21 & 19 \\ -0.004 & 0.484 & -2 & 2 \\ -0.004 & 1.107 & -4 & 4\end{array}$

Notes: The model also includes an intercept, team fixed effects for both competing team and a dummy coded 1 if the team $i$ plays at home. 
TABLE 2

Estimates of the Team Production Function

Dependent variable

Goal difference

Estimation approach

OLS

$\beta$-coef.

Std. Error

Attacking plays

Difference in shots on target

Difference in shots off target

$0.199 * * \quad 0.012$

Difference in shots hitting (goal net) woodwork

$-0.017 * \quad 0.006$

$0.022 \quad 0.039$

Defensive plays

Difference in clearances, blocks and interceptions

$0.010 * * \quad 0.002$

Difference in saves to shots ratio by the goalkeeper

$3.593 * * \quad 0.132$

Difference in number of times the ball was caught by the goalkeeper

0.012

Difference in number of times the ball was dropped by the goalkeeper

0.032

0.046

\section{Efficiency plays}

Difference in \% successful passes

$0.297 \quad 0.544$

Difference in \% successful flicks

Difference in \% successful crossings

$-0.001$

0.100

Difference in \% successful dribblings

$0.739 * * \quad 0.258$

Difference in \% successful tackles

0.276

0.216

Aggressive plays

Difference in number of red cards

Difference in number of yellow cards

0.061

0.215

Difference in fouls conceded in one's own third of the playing area

$-0.328 * * \quad 0.069$

$-0.065^{* *} \quad 0.013$

Difference in fouls conceded not in one's own third of the playing area

$-0.010 \quad 0.010$

Difference in penalties conceded (fouls conceded in penalty area)

$0.006 \quad 0.005$

Difference in hands conceded

$-0.155^{* *} \quad 0.049$

$\mathrm{R}^{2}$

0.017

0.027

Number of observations

0.72

1530

Notes: Ordinary least squares estimates. The dependent variable is the goal difference between the two competing teams. The model additionally includes an intercept, a dummy variable home advantage denoted 1 if the considered team is playing at home ( 0 otherwise), and team fixed effects for both competing teams. Standard errors are White-heteroskedasticity robust. Significance levels (two-tailed): * $5 \%$; ${ }^{\star *} 1 \%$. 
TABLE 3

Quantiles of the Market Value Distribution

\begin{tabular}{cc}
\hline Quantiles & Kicker market values \\
\hline $1 \%$ & $200,000 €$ \\
$5 \%$ & $500,000 €$ \\
$10 \%$ & $750,000 €$ \\
$25 \%$ & $1,000,000 €$ \\
$50 \%$ & $1,500,000 €$ \\
$75 \%$ & $2,500,000 €$ \\
$90 \%$ & $4,500,000 €$ \\
$95 \%$ & $5,500,000 €$ \\
$99 \%$ & $8,000,000 €$ \\
\hline
\end{tabular}


TABLE 4

Variables and Descriptive Statistics of the Main Regression

\begin{tabular}{|c|c|c|c|}
\hline Variable & Description & Mean & $S D$ \\
\hline \multicolumn{4}{|l|}{ Dependent variable } \\
\hline LNVALUE & $\begin{array}{l}\text { Logarithm of a player's market value at the end of the } \\
\text { season according to the Kicker soccer magazine }\end{array}$ & 14.28 & 0.73 \\
\hline \multicolumn{4}{|l|}{ Independent variables } \\
\hline \multicolumn{4}{|l|}{ Talent variables } \\
\hline GOALS & Goals & 2.52 & 3.77 \\
\hline ASSISTS & Assists & 1.79 & 2.25 \\
\hline SHOTS ON TARGET & Number of shots on target & 8.41 & 10.08 \\
\hline SHOTS OFF TARGET & Number of shots off target & 10.37 & 10.07 \\
\hline \multicolumn{2}{|c|}{ CLEARANCES, BLOCKS, INTERCEPTIONS Clearances, blocks and interceptions } & 66.96 & 76.08 \\
\hline SAVES TO SHOTS RATIO & Save to shots ratio by the goalkeeper & 0.06 & 0.19 \\
\hline CROSS SUCCESS RATE & $\%$ successful crossings & 0.21 & 0.17 \\
\hline RED CARDS & Number of red cards & 0.18 & 0.43 \\
\hline YELLOW CARDS & Number of yellow cards & 3.29 & 2.61 \\
\hline PENALTY CONCEDED & Number of fouls conceded in penalty area & 0.19 & 0.48 \\
\hline \multicolumn{4}{|l|}{ Popularity variable } \\
\hline $\begin{array}{l}\text { NON-PERFORMANCE-RELATED PRESS } \\
\text { CITATIONS }\end{array}$ & $\begin{array}{l}\text { Residuals of a regression of the logarithm of citations } \\
\text { in over } 20 \text { German newspapers and weekly } \\
\text { magazines on individual talent measures }\end{array}$ & 0.00 & 1.24 \\
\hline \multicolumn{4}{|l|}{ Control variables } \\
\hline AGE & Player's age & 25.93 & 4.06 \\
\hline AGESQ & Squared term of $A G E$ & 688.76 & 215.48 \\
\hline APPEARANCES & Appearances in the considered season & 20.94 & 9.24 \\
\hline PREVIOUS APPEARANCES & Accumulated appearances before the considered & 70.75 & 79.61 \\
\hline ATTACKER & Attacker (dummy) & 0.23 & \\
\hline MIDFIELDER & Midfielder (dummy) & 0.39 & \\
\hline RELEGATION & Club was relegated at the end of the season & 0.03 & \\
\hline \multicolumn{2}{|l|}{ Number of players } & \multicolumn{2}{|c|}{605} \\
\hline \multicolumn{2}{|l|}{ Observations } & \multicolumn{2}{|c|}{1370} \\
\hline
\end{tabular}

Notes: The model also includes an intercept and team fixed effects. 
TABLE 5

Determinants of a Star's Market Value

\begin{tabular}{|c|c|c|c|c|c|c|c|c|c|c|}
\hline \multirow{3}{*}{$\begin{array}{l}\text { Dependent variable } \\
\text { Estimation approach }\end{array}$} & \multicolumn{10}{|c|}{ Logarithm of individual market values according to Kicker } \\
\hline & \multicolumn{2}{|c|}{ OLS } & \multicolumn{2}{|c|}{ Fixed Effects } & \multicolumn{2}{|c|}{$90 \%$ Quantile Reg. } & \multicolumn{2}{|c|}{95 Quantile Reg. } & \multicolumn{2}{|c|}{ 98\% Quantile Reg. } \\
\hline & $\beta$-coef. & Std. Err. & $\beta$-coef. & Std. Err. & $\beta$-coef. & Std. Err. & $\beta$-coef. & Std. Err. & $\beta$-coef. & Std. Err. \\
\hline \multicolumn{11}{|l|}{ Talent indicators } \\
\hline Goals & $0.039 * *$ & 0.009 & $0.040^{\star \star}$ & 0.009 & 0.060 ** & 0.014 & $0.045^{* *}$ & 0.016 & $0.039 *$ & 0.022 \\
\hline Assists & $0.039 * *$ & 0.007 & 0.038 ** & 0.008 & $0.028 * *$ & 0.010 & 0.020 & 0.011 & 0.017 & 0.012 \\
\hline Shots on target & 0.006 & 0.004 & 0.002 & 0.003 & 0.007 & 0.008 & $0.017^{*}$ & 0.008 & 0.018 & 0.010 \\
\hline Shots off target & 0.002 & 0.003 & 0.000 & 0.000 & -0.001 & 0.005 & -0.009 & 0.005 & 0.002 & 0.007 \\
\hline Clearances, blocks, intercept. & $0.001 * *$ & 0.000 & 0.000 & 0.000 & $0.001 *$ & 0.001 & $0.002 *$ & 0.001 & $0.001 * *$ & 0.001 \\
\hline Saves to shots ratio & $0.366^{\star *}$ & 0.136 & 0.938 & 0.745 & $0.591^{\star *}$ & 0.164 & $0.488 *$ & 0.231 & $0.473 *$ & 0.244 \\
\hline Cross completion rate & -0.043 & 0.092 & -0.155 & 0.096 & 0.077 & 0.171 & -0.140 & 0.161 & -0.256 & 0.232 \\
\hline Red cards & 0.035 & 0.030 & -0.056 & 0.032 & 0.061 & 0.068 & 0.117 & 0.083 & 0.221 & 0.100 \\
\hline Yellow cards & 0.001 & 0.006 & 0.004 & 0.007 & 0.002 & 0.011 & 0.003 & 0.011 & 0.001 & 0.015 \\
\hline Penalties conceded & 0.018 & 0.026 & 0.000 & 0.030 & 0.031 & 0.041 & 0.022 & 0.045 & -0.017 & 0.049 \\
\hline Joint sig. of talent (F-statistic) & \multicolumn{2}{|c|}{$17.87^{* *}$} & \multicolumn{2}{|c|}{$11.78^{* *}$} & \multicolumn{2}{|c|}{$11.56^{\star \star}$} & \multicolumn{2}{|c|}{$7.04^{* *}$} & \multicolumn{2}{|c|}{$7.62^{* *}$} \\
\hline \multicolumn{11}{|l|}{ Popularity indicator } \\
\hline $\begin{array}{l}\text { Non-performance-related } \\
\text { press citations }\end{array}$ & $0.135 * *$ & 0.017 & 0.125 ** & 0.019 & $0.115 * *$ & 0.021 & $119^{* *}$ & 0.025 & 0.104 ** & 0.026 \\
\hline \multicolumn{11}{|l|}{ Controls } \\
\hline Intercept & $11.313^{* *}$ & 0.584 & $11.345^{* *}$ & 1.240 & $12.303^{* *}$ & 0.828 & 14.042 ** & 1.173 & $14.483^{* *}$ & 1.225 \\
\hline Age & $0.207^{* *}$ & 0.045 & $0.386^{* *}$ & 0.089 & $0.183^{* *}$ & 0.066 & 0.065 & 0.086 & 0.429 ** & 0.103 \\
\hline Age s & $-0.004 * *$ & 0.001 & $-0.011 * *$ & 0.002 & $-0.004 * *$ & 0.001 & -0.002 & 0.002 & $-0.008 * *$ & 0.002 \\
\hline Appearances & $0.026 * *$ & 0.003 & 0.014 ** & 0.004 & $0.019 * *$ & 0.004 & $0.014^{* *}$ & 0.005 & 0.001 & 0.006 \\
\hline Previous appearances & 0.000 & 0.000 & $0.003^{* *}$ & 0.001 & 0.000 & 0.000 & 0.000 & 0.001 & -0.001 & 0.001 \\
\hline Relegation & -0.134 & 0.094 & -0.137 & 0.112 & 0.252 & 0.290 & 0.395 & 0.298 & 0.259 & 0.367 \\
\hline Position fixed effects & yes & & yes & & yes & & yes & & yes & \\
\hline Team fixed effects & yes & & yes & & yes & & yes & & yes & \\
\hline (Pseudo) $R^{2}$ & \multirow{2}{*}{\multicolumn{2}{|c|}{$\begin{array}{l}0.63 \\
1370\end{array}$}} & \multirow{2}{*}{\multicolumn{2}{|c|}{$\begin{array}{c}0.46 \text { (within) } \\
1370\end{array}$}} & \multirow{2}{*}{\multicolumn{2}{|c|}{$\begin{array}{l}0.44 \\
1370\end{array}$}} & \multirow{2}{*}{\multicolumn{2}{|c|}{$\begin{array}{l}0.44 \\
1370\end{array}$}} & \multirow{2}{*}{\multicolumn{2}{|c|}{$\begin{array}{l}0.61 \\
1370\end{array}$}} \\
\hline Number of observations & & & & & & & & & & \\
\hline
\end{tabular}

Notes: The sample includes players who appeared for at least half an hour in the highest German soccer league during the seasons $2001 / 02$ until 2005/06. As the dependent variable is missing if the player left the league after the season, we tested for potential attrition bias. Attrition probability is, however, not affected by the player's mean market value, conditional on the explanatory variables. Standard errors in the OLS and FE procedures are White-robust and clustered at the player level. The standard errors of the quantile specifications are clustering adjusted standard errors based on 1000 bootstrap replications. Significance levels (two-tailed): ${ }^{*} 5 \%$; ${ }^{* *} 1 \%$. 
TABLE 6

Cross-Sectional Estimates of the Determinants of a Star's Market Value Using a Second Data Source

\begin{tabular}{|c|c|c|c|c|c|c|c|c|}
\hline \multirow{3}{*}{$\begin{array}{l}\text { Dependent variable } \\
\text { Estimation approach }\end{array}$} & \multicolumn{8}{|c|}{ Logarithm of individual market values according to Transfermarkt } \\
\hline & \multicolumn{2}{|c|}{ OLS } & \multicolumn{2}{|c|}{$90 \%$ Quantile Reg. } & \multicolumn{2}{|c|}{ 95\% Quantile Reg. } & \multicolumn{2}{|c|}{ 98\% Quantile Reg. } \\
\hline & $\beta$-coef. & Std. Err. & $\beta$-coef. & Std. Err. & $\beta$-coef. & Std. Err. & $\beta$-coef. & Std. Err. \\
\hline \multicolumn{9}{|l|}{ Talent indicators } \\
\hline Goals & $0.080 * *$ & 0.012 & $0.090 * *$ & 0.020 & $0.095 * *$ & 0.022 & $0.096 * *$ & 0.023 \\
\hline Assists & $0.071 * *$ & 0.017 & $0.093 * *$ & 0.025 & $0.079 * *$ & 0.029 & $0.068 *$ & 0.030 \\
\hline Shots on target & -0.024 & 0.023 & -0.044 & 0.118 & -0.053 & 0.137 & -0.120 & 0.146 \\
\hline Shots off target & 0.023 & 0.022 & 0.043 & 0.117 & 0.051 & 0.135 & 0.113 & 0.146 \\
\hline Clearances, blocks, interceptions & $0.003 * *$ & 0.001 & 0.002 & 0.002 & 0.002 & 0.002 & 0.002 & 0.002 \\
\hline Saves to shots ratio & $0.726 * *$ & 0.240 & 0.457 & 0.401 & 0.067 & 0.486 & -0.147 & 0.472 \\
\hline Cross completion rate & -0.029 & 0.172 & 0.079 & 0.262 & -0.147 & 0.289 & 0.051 & 0.292 \\
\hline Red cards & 0.111 & 0.078 & 0.186 & 0.188 & 0.268 & 0.215 & 0.367 & 0.236 \\
\hline Yellow cards & 0.022 & 0.016 & 0.044 & 0.025 & 0.043 & 0.029 & 0.035 & 0.029 \\
\hline Penalties conceded & 0.011 & 0.065 & -0.029 & 0.097 & -0.131 & 0.117 & -0.114 & 0.124 \\
\hline Joint sig. of talent (F-statistic) & \multicolumn{2}{|c|}{$16.30^{* \star}$} & \multicolumn{2}{|c|}{$7.52^{* *}$} & \multicolumn{2}{|c|}{$5.78^{\star *}$} & \multicolumn{2}{|c|}{$4.97^{* *}$} \\
\hline \multicolumn{9}{|l|}{ Popularity indicator } \\
\hline $\begin{array}{l}\text { Non-performance-related press } \\
\text { citations }\end{array}$ & $0.255^{* *}$ & 0.042 & $0.258 * *$ & 0.054 & $0.300 * *$ & 0.059 & $0.302 * *$ & 0.062 \\
\hline \multicolumn{9}{|l|}{ Controls } \\
\hline Intercept & 5.306 ** & 1.041 & 7.867 ** & 1.915 & 9.204 ** & 2.119 & $8.219 * *$ & 2.174 \\
\hline Age & $0.607^{* *}$ & 0.076 & $0.510 * *$ & 0.143 & $0.418 * *$ & 0.157 & 0.549 & 0.166 \\
\hline Age squared & $-0.011 * *$ & 0.001 & $-0.010 * *$ & 0.003 & $-0.008 * *$ & 0.003 & -0.010 & 0.003 \\
\hline Appearances & $0.019 * *$ & 0.005 & 0.001 & 0.008 & 0.007 & 0.009 & 0.011 & 0.010 \\
\hline Previous appearances & $-0.001 * *$ & 0.001 & -0.001 & 0.001 & -0.001 & 0.001 & -0.001 & 0.001 \\
\hline Position fixed effects & yes & & yes & & yes & & yes & \\
\hline Team fixed effects & yes & & yes & & yes & & yes & \\
\hline (Pseudo) $R^{2}$ & \multicolumn{2}{|c|}{0.70} & \multicolumn{2}{|c|}{0.56} & \multicolumn{2}{|c|}{0.56} & \multicolumn{2}{|c|}{0.61} \\
\hline Number of observations & \multicolumn{2}{|c|}{427} & \multicolumn{2}{|c|}{427} & \multicolumn{2}{|c|}{427} & \multicolumn{2}{|c|}{427} \\
\hline
\end{tabular}

Notes: The sample includes all players who played for at least half an hour in the highest German soccer league during the season 2004/05. Standard errors in the OLS are White-robust. The standard errors of the quantile specifications are based on 1000 bootstrap replications. Significance levels (two-tailed): ${ }^{*} 5 \% ;{ }^{* *} 1 \%$. 
TABLE 7

Revenue Performance Sensitivity

\begin{tabular}{|c|c|c|c|c|c|c|c|c|c|c|}
\hline \multirow{3}{*}{$\begin{array}{l}\text { Dependent variables } \\
\text { Estimation approach }\end{array}$} & \multicolumn{2}{|c|}{ Ln(Total R.) } & \multicolumn{2}{|c|}{ Ln(Match Day R.) } & \multirow{2}{*}{\multicolumn{2}{|c|}{$\begin{array}{l}\text { Ln(Sponsoring R.) } \\
\text { Team Fixed Effects }\end{array}$}} & \multicolumn{2}{|c|}{ Ln(Broacasting R.) } & \multicolumn{2}{|c|}{ Ln(Miscellaneous R.) } \\
\hline & & & & & & & & & & \\
\hline & $\beta$-coef. & Std. Err. & $\beta$-coef. & Std. Err. & $\beta$-coef. & Std. Err. & $\beta$-coef. & Std. Err. & $\beta$-coef. & Std. Err. \\
\hline Winning Percentage $_{t-1}$ & $1.181 * *$ & 0.412 & 1.632 ** & 0.410 & $1.368 * *$ & 0.422 & 1.749 * & 0.659 & 0.286 & 1.362 \\
\hline Stadium Capacity $\mathrm{t}$ & 0.005 & 0.008 & $0.022 *$ & 0.008 & 0.010 & 0.009 & -0.009 & 0.008 & 0.005 & 0.010 \\
\hline \multicolumn{11}{|l|}{ League Average } \\
\hline$R^{2}$ (within) & \multicolumn{2}{|c|}{0.16} & \multicolumn{2}{|c|}{0.43} & \multicolumn{2}{|c|}{0.17} & \multicolumn{2}{|c|}{0.20} & \multicolumn{2}{|c|}{0.01} \\
\hline Number of observations & \multicolumn{2}{|c|}{75} & \multicolumn{2}{|c|}{75} & \multicolumn{2}{|c|}{75} & \multicolumn{2}{|c|}{75} & \multicolumn{2}{|c|}{75} \\
\hline
\end{tabular}

Notes: Team fixed effects estimations. The sample includes all teams appearing in the highest German soccer league during the seasons $2001 / 02$ until 2005/06 except the teams that were promoted for the corresponding season. Standard errors are White-robust and clustered at the team level to adjust for serial error correlation. Significance levels (two-tailed): * $5 \%$; ${ }^{* *} 1 \%$. 


\section{TABLE 8}

Separate Quantile Regressions for Offensive and Defensive Players

\begin{tabular}{|c|c|c|c|c|c|c|c|c|}
\hline Dependent variable & \multicolumn{8}{|c|}{ Logarithm of individual market values according to Kicker } \\
\hline Estimation approach & \multicolumn{2}{|c|}{ OLS } & \multicolumn{2}{|c|}{ 95\% Quantile Reg. } & \multicolumn{2}{|c|}{ OLS } & \multicolumn{2}{|c|}{ 95\% Quantile Reg. } \\
\hline Subsample & \multicolumn{4}{|c|}{$\begin{array}{c}\text { Offensive players } \\
\text { (attackers and midfielders) }\end{array}$} & \multicolumn{4}{|c|}{$\begin{array}{c}\text { Defensive players } \\
\text { (defenders and goalkeepers) }\end{array}$} \\
\hline & $\beta$-coef. & Std. Err. & $\beta$-coef. & Std. Err. & $\beta$-coef. & Std. Err. & $\beta$-coef. & Std. Err. \\
\hline \multicolumn{9}{|l|}{ Talent indicators } \\
\hline Goals & $0.040 * *$ & 0.009 & $0.043 *$ & 0.019 & & & & \\
\hline Assists & $0.040 * *$ & 0.008 & 0.027 * & 0.012 & & & & \\
\hline Shots on target & 0.005 & 0.004 & 0.012 & 0.009 & & & & \\
\hline Shots off target & 0.004 & 0.003 & -0.006 & 0.006 & & & & \\
\hline Clearances, blocks, interceptions & & & & & $0.001 *$ & 0.000 & $0.002 * *$ & 0.001 \\
\hline Saves to shots ratio & & & & & 0.175 & 0.133 & 0.237 & 0.199 \\
\hline Cross completion rate & 0.159 & 0.132 & 0.001 & 0.274 & -0.184 & 0.132 & -0.232 & 0.219 \\
\hline Red cards & 0.013 & 0.046 & 0.226 * & 0.098 & 0.034 & 0.040 & 0.031 & 0.078 \\
\hline Yellow cards & 0.013 & 0.007 & 0.017 & 0.013 & 0.001 & 0.012 & -0.008 & 0.019 \\
\hline Penalties conceded & 0.040 & 0.052 & -0.014 & 0.107 & -0.010 & 0.033 & -0.011 & 0.045 \\
\hline Joint sig. of talent (F-statistic) & \multicolumn{2}{|c|}{$25.98^{* *}$} & \multicolumn{2}{|c|}{$7.56^{* *}$} & \multicolumn{2}{|c|}{1.63} & \multicolumn{2}{|c|}{1.40} \\
\hline \multicolumn{9}{|l|}{ Popularity indicator } \\
\hline $\begin{array}{l}\text { Non-performance-related press } \\
\text { citations }\end{array}$ & $0.100 * *$ & 0.020 & 0.074 * & 0.030 & $0.174^{* *}$ & 0.028 & $0.147^{* *}$ & 0.036 \\
\hline (Pseudo) $R^{2}$ & \multicolumn{2}{|c|}{0.63} & \multicolumn{2}{|c|}{0.44} & \multicolumn{2}{|c|}{0.61} & \multicolumn{2}{|c|}{0.49} \\
\hline Number of observations & \multicolumn{2}{|c|}{852} & \multicolumn{2}{|c|}{852} & \multicolumn{2}{|c|}{518} & \multicolumn{2}{|c|}{518} \\
\hline
\end{tabular}

Notes: Standard errors in the OLS procedure are White-robust and clustered at the player level. The standard errors of the quantile specifications are clustering adjusted standard errors based on 1000 bootstrap replications. The sample includes players who appeared for at least half an hour in the highest German soccer league during the seasons 2001/02 until 2005/06. All models additionally control for the player's age, age squared, the number of appearances during the season and before, unobserved team heterogeneity, the team's relegation status, and an intercept. Significance levels (two-tailed): ${ }^{*} 5 \%$; ${ }^{* *} 1 \%$. 
TABLE 9

Separate Quantile Regressions for Offensive and Defensive Players using Expert Evaluations as Talent Indicator

\begin{tabular}{|c|c|c|c|c|c|c|c|c|}
\hline \multirow{2}{*}{$\begin{array}{l}\text { Dependent variable } \\
\text { Estimation approach }\end{array}$} & \multicolumn{8}{|c|}{ Logarithm of individual market values according to Kicker } \\
\hline & \multicolumn{2}{|c|}{ OLS } & \multicolumn{2}{|c|}{ 95\% Quantile Reg. } & \multicolumn{2}{|c|}{ OLS } & \multicolumn{2}{|c|}{ 95\% Quantile Reg. } \\
\hline \multirow[t]{2}{*}{ Subsample } & \multicolumn{4}{|c|}{$\begin{array}{c}\text { Offensive players } \\
\text { (attackers and midfielders) }\end{array}$} & \multicolumn{4}{|c|}{$\begin{array}{c}\text { Defensive players } \\
\text { (defenders and goalkeepers) }\end{array}$} \\
\hline & $\beta$-coef. & Std. Err. & $\beta$-coef. & Std. Err. & $\beta$-coef. & Std. Err. & $\beta$-coef. & Std. Err. \\
\hline \multicolumn{9}{|l|}{ Talent indicators } \\
\hline Expert evaluations & 0.488 ** & 0.064 & $0.594 * *$ & 0.088 & $0.305 * *$ & 0.068 & 0.253 * & 0.116 \\
\hline \multicolumn{9}{|l|}{ Popularity indicator } \\
\hline $\begin{array}{l}\text { Non-performance-related } \\
\text { press citations }\end{array}$ & $0.092 * *$ & 0.019 & $0.072 * *$ & 0.034 & $0.167 * *$ & 0.028 & $0.118^{* *}$ & 0.033 \\
\hline (Pseudo) $R^{2}$ & \multicolumn{2}{|c|}{0.57} & \multicolumn{2}{|c|}{0.39} & \multicolumn{2}{|c|}{0.66} & \multicolumn{2}{|c|}{0.49} \\
\hline Number of observations & \multicolumn{2}{|c|}{852} & \multicolumn{2}{|c|}{852} & \multicolumn{2}{|c|}{518} & \multicolumn{2}{|c|}{518} \\
\hline
\end{tabular}

Notes: Standard errors in the OLS procedure are White-robust and clustered at the player level. The standard errors of the quantile specifications are clustering adjusted standard errors based on 1000 bootstrap replications. The sample includes players who appeared for at least half an hour in the highest German soccer league during the seasons 2001/02 until 2005/06. All models additionally control for the player's age, age squared, the number of appearances during the season and before, unobserved team heterogeneity, the team's relegation status, and an intercept. Significance levels (two-tailed): ${ }^{*} 5 \%$; ** $1 \%$. 


\section{APPENDIX}

TABLE 10

Popularity Regressed on Field Performance

Dependent variable

Ln(Press citations)

Estimation approach

Pooled OLS

\begin{tabular}{lcr}
\hline & Beta & $t$-value \\
\hline Goals & $0.295^{* *}$ & 5.220 \\
Assists & $0.157^{* *}$ & 4.760 \\
Shots on target & -0.010 & -0.130 \\
Shots off target & $0.116^{*}$ & 2.200 \\
Clearances, blocks and interceptions & $0.137^{* *}$ & 3.760 \\
Saves to shots ratio by the goalkeeper & $0.225^{* *}$ & 5.290 \\
\% successful crossings & $0.021^{*}$ & 0.860 \\
Number of red cards & $0.052^{*}$ & 2.160 \\
Number of yellow cards & $0.070^{*}$ & 2.350 \\
Penalty conceded & -0.010 & -0.420 \\
$R^{2}$ & \multicolumn{2}{c}{0.24} \\
Number of observations & \multicolumn{2}{c}{1370} \\
\hline
\end{tabular}

Notes: The Beta coefficients illustrate the change in the dependent variable if the regressor varies by one standard deviation. t-values are computed using the White-heteroskedasticity robust standard errors clustered at the player level. The sample includes players appearing in the first German soccer leagure for more than half an hour during the seasons 2001/02 until 2004/05. Significance levels (two-tailed): ${ }^{*} 5 \% ;{ }^{* \star} 1 \%$. 
TABLE 11

Test of Potential Selection Bias

Dependent variable

Attrition (0/1)

Estimation approach

Probit

$d F / d x \quad$ Std. Err.

Individual mean of the dependent variable of the main regression

Individual mean of market values

$-0.039 \quad 0.027$

Explanatory variables of the main regression

Goals

Assists

$-0.023 * 0.011$

Shots on target

$0.000 \quad 0.011$

Shots off target

$0.009 \quad 0.005$

Clearances, blocks, interceptions

$-0.007 \quad 0.003$

Saves to shots ratio

$-0.001 \quad 0.000$

Cross completion rate

$-0.285 * 0.093$

Red cards

$-0.082 \quad 0.071$

Yellow cards

0.027

0.032

Penalties conceded

$-0.003 \quad 0.007$

Non-performance related press citations

$-0.030$

0.027

Age

$-0.013 \quad 0.012$

Age squared

$-0.029 \quad 0.031$

Appearances

$0.001 * 0.001$

Previous appearances

$-0.017^{* *} 0.002$

Position fixed effects

$0.000 \quad 0.000$

Team fixed effects

yes

yes

Additional control variable

Relegation

0.764 ** 0.026

(Pseudo) $R^{2}$

0.39

Number of observations

2006

Notes: Probit regression results with White-heteroskedasticity robust standard errors clustered at the player level. The first column reports the marginal effects. The results show that attrition propensity is not affected by the individual mean of the dependent variable, conditional on the explanatory variables of the main model and a dummy variable Relegation equaling 1 if the player's team was demoted and 0 otherwise. Significance levels (two-tailed): * $5 \%$; ** $1 \%$. 
TABLE 12

Seasonal Team Production Function Estimation using Aggregated Talent Indicators

\begin{tabular}{lcc}
\hline Dependent variable & \multicolumn{2}{c}{ Winning Percentage } \\
Estimation approach & \multicolumn{2}{c}{ Team Fixed Effects } \\
\hline & $0.0067^{* *}$ & 0.0013 \\
\hline Goals & -0.0007 & 0.0017 \\
Assists & -0.0001 & 0.0005 \\
Shots on target & -0.0003 & 0.0004 \\
Shots off target & 0.0000 & 0.0000 \\
Clearances, blocks, interceptions & $0.6493^{* *}$ & 0.1212 \\
Saves to shots ratio & 0.2024 & 0.1915 \\
Cross completion rate & -0.0033 & 0.0026 \\
Red cards & 0.0026 & 0.0006 \\
Yellow cards & -0.0008 & 0.0031 \\
Penalties conceded & -0.1957 & 0.1151 \\
Constant & \multicolumn{3}{c}{0.69} \\
$R^{2}$ (within) & \multicolumn{2}{c}{90} \\
Number of observations & \multicolumn{3}{c}{. }
\end{tabular}

Notes: The dependent variable winning percentage is calculated by dividing the achieved points at the end of the season by the maximum possible points. The standard errors are White-heteroskedasticity robust and clustered at the team level. The sample includes all teams of the highest German soccer league during the seasons 2001/02 until 2005/06. Significance levels (two-tailed): ${ }^{*} 5 \%$; ${ }^{* *} 1 \%$. 
FIGURE 1

Distribution of the Logarithm of the Players' Market Values

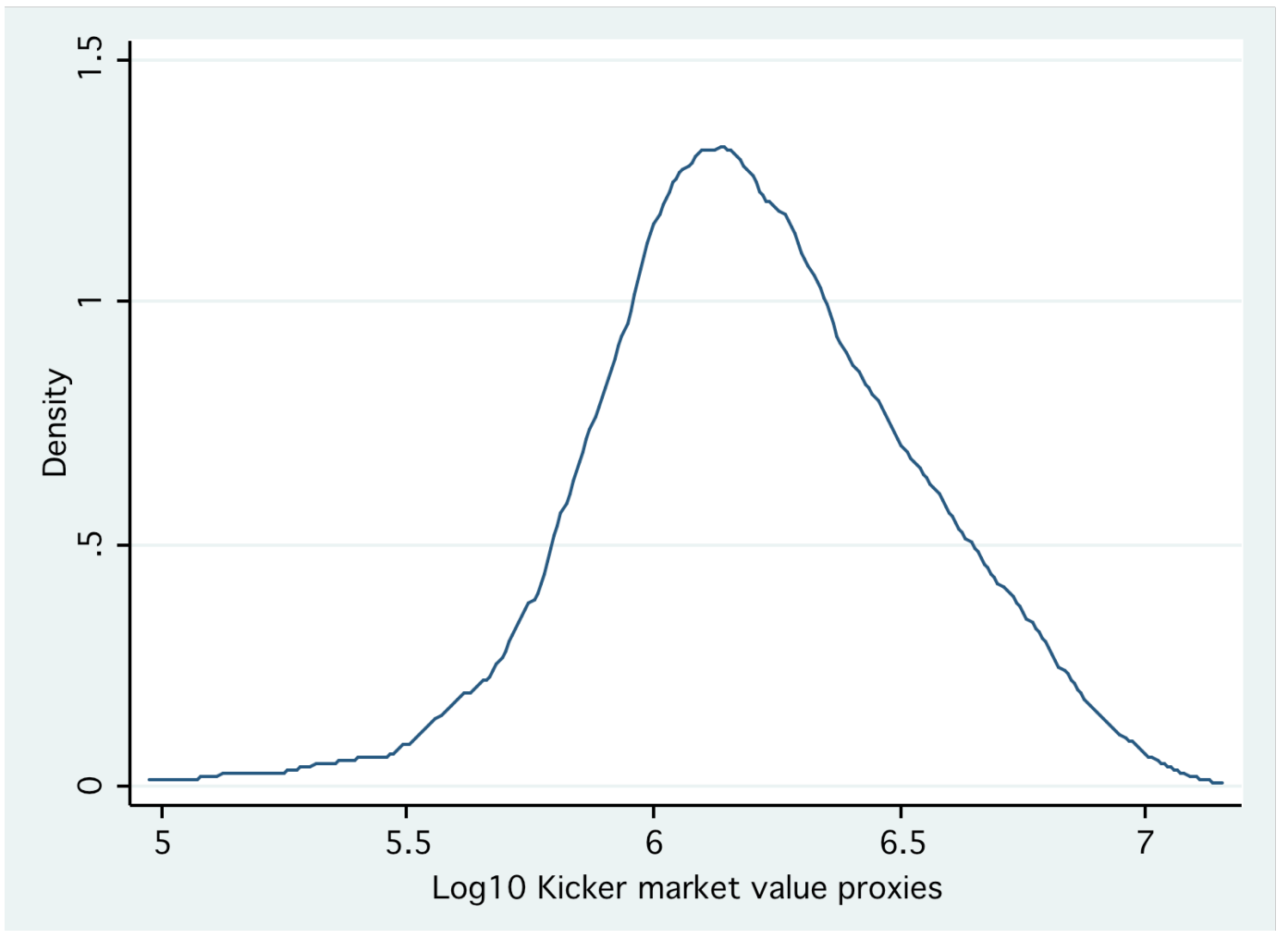

Notes: Figure 1 illustrates nonparametric kernel estimates of the distribution of the $\log 10$ of individual market value proxies published in the Kicker soccer magazine. The sample size is 1370. We used an Epanechnikov kernel and "optimal" bandwidth. 